Check for updates

Cite this: React. Chem. Eng., 2019, 4,1284

Received 27th March 2019,

Accepted 2nd May 2019

DOI: 10.1039/c9re00137a

rsc.li/reaction-engineering

\title{
Estimating speciation of aqueous ammonia solutions of ammonium bicarbonate: application of least squares methods to infrared spectra†
}

\author{
Federico Milella (iD) and Marco Mazzotti (D)*
}

\begin{abstract}
The knowledge of the speciation and of the supersaturation of aqueous solutions of $\mathrm{CO}_{2}$ and $\mathrm{NH}_{3}$ is pivotal for the design and optimization of unit operations, e.g. absorption or crystallization, in the framework of ammonia-based $\mathrm{CO}_{2}$ capture systems. For this information to be available, however, complex analytical techniques and significant experimental effort are required. This work introduces a methodology for the estimation of the concentration of species in aqueous ammonia solutions of ammonium bicarbonate by using attenuated total reflection infrared spectroscopy (ATR-FTIR) and spectral modeling based on least squares methods. In particular, the methodology can be exploited for the on-line monitoring of the liquid composition of crystallizing suspensions of ammonium bicarbonate for which the information on the speciation is combined with a rigorous thermodynamic model to compute the activity-based supersaturation. Finally, this work paves the way for the estimation of the crystallization kinetics of ammonium bicarbonate formation in aqueous ammonia solutions which is of great importance for the design of industrial $\mathrm{CO}_{2}$ capture absorption processes that exploit solid formation.
\end{abstract}

\section{Introduction}

The characterization of the $\mathrm{CO}_{2}-\mathrm{NH}_{3}-\mathrm{H}_{2} \mathrm{O}$ system in terms of the liquid phase reactions and of the solid-liquid equilibria that can be established at the relevant operating conditions is based on extensive experimental work carried out almost one hundred years ago. ${ }^{1-4}$ Furthermore, thermodynamic models capable of computing such equilibria have been developed with the aim of designing and optimizing relevant industrial processes such as wastewater and flue gas treatment, and enhanced oil recovery. ${ }^{5,6}$ As an example, the Chilled Ammonia Process (CAP) developed by Alstom Power captures greenhouse gases from large $\mathrm{CO}_{2}$ point sources such as power plants by means of aqueous ammonia solutions. ${ }^{7}$ Several variants of the process exist; among them the so-called Controlled Solid Formation-Chilled Ammonia Process (CSF-CAP) allows for the precipitation of ammonium bicarbonate $\left(\mathrm{NH}_{4} \mathrm{HCO}_{3}\right.$, in the following also "BC") to lower the specific energy demand of the process by increasing the $\mathrm{CO}_{2}$ uptake capacity of the solvent system. ${ }^{7}$ In this process, the information about the phase equilibria and the kinetic effects of chemical reactions and mass transfer are key for the design

Institute of Process Engineering, ETH Zurich, 8092 Zurich, Switzerland.

E-mail: marco.mazzotti@ipe.mavt.ethz.ch

$\dagger$ Electronic supplementary information (ESI) available. See DOI: 10.1039/ c9re00137a and optimization of a continuous crystallization section fully integrated with the rest of the capture plant. ${ }^{8}$ Retrieving crystallization kinetics of $\mathrm{BC}$ for this system is complicated by the high volatility of the solutes, ${ }^{9}$ i.e. $\mathrm{NH}_{3}$ and $\mathrm{CO}_{2}$, and requires the information on the speciation of the solution for the computation of the driving force of the crystallization process, i.e. the supersaturation. In this regard, the use of available thermodynamic models, ${ }^{5,6}$ usually fitted on vapor-liquid equilibrium data and only on a limited amount of liquid speciation data, ${ }^{10,11}$ leads to inaccurate estimates of the BC solubility.

The call for an improved accuracy in the description of the solid-liquid equilibrium of $\mathrm{BC}$ in aqueous ammonia solutions motivated this work in which a methodology for the measurement of the speciation of aqueous ammonia solutions of ammonium bicarbonate is developed. attenuated total reflection Fourier-transform infrared spectroscopy (ATR-FTIR) ${ }^{12,13}$ has been used to measure the overall carbon concentration, as well as the equilibrium speciation in solution. The advantage of such a technique over Raman spectroscopy, also used to study properties of this system, ${ }^{14-17}$ is that it allows for liquidphase concentration monitoring exclusively, in spite of the presence of a solid phase suspended. The analysis of the IR spectrum of the mixtures reveals complex overlaps of the bands of the individual components that have been resolved by means of a simple but effective classical least squares (CLS) method. Then, the information retrieved has been used to estimate the solutes concentration while fulfilling the mass and charge balances in solution. 
The BC solubility and the concentration estimates of the species in saturated aqueous ammonia solutions of BC at different nominal ammonia concentrations in the solvent (between 0 and $3 \% \mathrm{wt}$ ) have been, at first, compared to the literature data in the temperature range $8-23^{\circ} \mathrm{C}$. Then, they have been used to improve the accuracy of the description of the liquid-solid equilibrium of ammonium bicarbonate by using a thermodynamic model.

The article is organized as follows: section 2 introduces the thermodynamics of the system and, in particular, it discusses the electrolyte species that form in aqueous solutions of ammonia and $\mathrm{CO}_{2}$ and the chemical reactions involved. In section 3 , the experimental setup, the analytical methods and the characterization techniques used are discussed with particular emphasis on the preparation of the standard analytes for the ATRFTIR calibration measurements. Section 4 provides a description of the mathematical model used to resolve complex overlapping spectra and the estimation of the concentration of the individual species. Finally, in section 5 the methodology is applied to the case of real mixtures containing $\mathrm{CO}_{2}, \mathrm{NH}_{3}$, and $\mathrm{H}_{2} \mathrm{O}$ and a rigorous thermodynamic framework for the estimation of the supersaturation of aqueous ammonia solutions of ammonium bicarbonate is established.

\section{The $\mathrm{CO}_{2}-\mathrm{NH}_{3}-\mathrm{H}_{2} \mathrm{O}$ system}

The $\mathrm{CO}_{2}-\mathrm{NH}_{3}-\mathrm{H}_{2} \mathrm{O}$ system is a highly volatile system characterized by the following vapor-liquid-solid equilibria., ${ }^{1,3,5,14}$

Vapor-liquid equilibria:

$$
\begin{gathered}
\mathrm{CO}_{2}(\mathrm{~g}) \rightleftharpoons \mathrm{CO}_{2}(\mathrm{aq}) \\
\mathrm{NH}_{3}(\mathrm{~g}) \rightleftharpoons \mathrm{NH}_{3}(\mathrm{aq}) \\
\mathrm{H}_{2} \mathrm{O}(\mathrm{g}) \rightleftharpoons \mathrm{H}_{2} \mathrm{O}
\end{gathered}
$$

Liquid speciation:

$$
\begin{gathered}
\mathrm{NH}_{3}(\mathrm{aq})+\mathrm{H}_{2} \mathrm{O} \rightleftharpoons \mathrm{NH}_{4}^{+}+\mathrm{OH}^{-} \\
\mathrm{CO}_{2}(\mathrm{aq})+\mathrm{H}_{2} \mathrm{O} \rightleftharpoons \mathrm{H}^{+}+\mathrm{HCO}_{3}^{-} \\
\mathrm{HCO}_{3}{ }^{-} \rightleftharpoons \mathrm{H}^{+}+\mathrm{CO}_{3}{ }^{2-} \\
\mathrm{H}_{2} \mathrm{O} \rightleftharpoons \mathrm{H}^{+}+\mathrm{OH}^{-} \\
\mathrm{NH}_{3}(\mathrm{aq})+\mathrm{HCO}_{3}{ }^{-} \rightleftharpoons \mathrm{NH}_{2} \mathrm{COO}^{-}+\mathrm{H}_{2} \mathrm{O}
\end{gathered}
$$

Solid-liquid equilibria:

$$
\begin{gathered}
\mathrm{NH}_{4}^{+}+\mathrm{HCO}_{3}^{-} \rightleftharpoons \mathrm{NH}_{4} \mathrm{HCO}_{3}(\mathrm{~s}) \\
\mathrm{NH}_{4}^{+}+\mathrm{NH}_{2} \mathrm{COO}^{-} \rightleftharpoons \mathrm{NH}_{2} \mathrm{COONH}_{4}(\mathrm{~s}) \\
2 \mathrm{NH}_{4}^{+}+\mathrm{CO}_{3}{ }^{2-}+\mathrm{H}_{2} \rightleftharpoons\left(\mathrm{NH}_{4}\right)_{2} \mathrm{CO}_{3} \cdot \mathrm{H}_{2} \mathrm{O}(\mathrm{s}) \\
4 \mathrm{NH}_{4}{ }^{+}+\mathrm{CO}_{3}{ }^{2-}+2 \mathrm{HCO}_{3}{ }^{-} \rightleftharpoons\left(\mathrm{NH}_{4}\right)_{2} \mathrm{CO}_{3} \cdot 2 \mathrm{NH}_{4} \mathrm{HCO}_{3}(\mathrm{~s})
\end{gathered}
$$

Due to the operating conditions adopted, the formation of $\mathrm{H}_{2} \mathrm{O}(\mathrm{s})$ (ice) has not been included in the set of solid-liquid equilibria considered.

Each of the equilibrium reaction of eqn (1) and (12) can be expressed as an equation of the form

$$
-\frac{\Delta G_{j}^{\circ}(T)}{R T}=\sum_{i} v_{i, j} \ln a_{i}
$$

where $\Delta G_{j}^{\circ}(T)$ is the change in standard state Gibbs free energy for reaction $j$ at the temperature $T, a_{i}$ is the activity of the $i$-th component, and $v_{i, j}$ is the stoichiometric coefficient of component $i$ in the reaction $j$. In order to compute the equilibrium phase composition of a mixture of $\mathrm{CO}_{2}, \mathrm{NH}_{3}$, and $\mathrm{H}_{2} \mathrm{O}$, eqn (1)-(8) must be brought in a form like eqn (13) and solved simultaneously. Extent of reactions can be used as iteration variables instead of the amounts of individual components to fulfill automatically the electroneutrality condition:

$$
m_{\mathrm{NH}_{4}{ }^{+}}+m_{\mathrm{H}^{+}}-m_{\mathrm{OH}^{-}}-m_{\mathrm{HCO}_{3}^{--}}-2 m_{\mathrm{CO}_{3}{ }^{--}}-m_{\mathrm{NH}_{2} \mathrm{COO}^{-}}=0
$$

where $m_{i}$ is the molality of the $i$-th component in the liquid phase.

After the equilibrium composition is found, eqn (9)-(12) are consulted to verify the presence of any solid phase. If one or more solid phases are formed, the corresponding equation(s) must be solved together with eqn (1)-(8).

Despite the fact that water and ammonia are completely miscible in the range of operating conditions explored, ammonia is considered a solute rather than a solvent. This choice allows for the application of the traditional tabulated standard state chemical potentials (NIST Tables) to ions and non-dissociated molecules for the equilibria calculations in water-ammonia-salt mixtures performed with the extendedUNIQUAC model as well as for the computation of the activity of $\mathrm{NH}_{3}(\mathrm{aq})$ in solution.

This work uses molality, $m$, as solute concentration (mole of component per unit mass of water), where the solvent itself is a reactive species. Additionally, the concentrations of the components must satisfy the following overall mass balances, in addition to the charge balance of eqn (14).

$$
\begin{gathered}
m_{\mathrm{C}, \mathrm{OL}}-m_{\mathrm{CO}_{2}}-m_{\mathrm{HCO}_{3}^{-}}-m_{\mathrm{CO}_{3}^{2-}}-m_{\mathrm{NH}_{2} \mathrm{COO}^{-}}-\sum_{j} v_{j, \mathrm{C}} m_{j}^{(s)}=0 \\
m_{\mathrm{N}, \mathrm{OL}}-m_{\mathrm{NH}_{3}}-m_{\mathrm{NH}_{4}^{+}}-m_{\mathrm{NH}_{2} \mathrm{COO}^{-}}-\sum_{j} v_{j, \mathrm{~N}} m_{j}^{(s)}=0
\end{gathered}
$$

In eqn (17), $m_{\mathrm{C},{ }_{\mathrm{OL}}}$ and $m_{N, \text {,L }}$ are the overall concentration of carbon and nitrogen in the system, $m_{j}^{(s)}, v_{j, \mathrm{C}}$ and $v_{j, \mathrm{~N}}$ are respectively the concentration of the $j$-th solid in the system (eqn (9)-(12)) and its carbon and nitrogen stoichiometric coefficients. 
In our experimental setup, the presence of a gas phase, consisting mainly of inert air, leads to the evaporation of $\mathrm{CO}_{2}, \mathrm{NH}_{3}$, and $\mathrm{H}_{2} \mathrm{O}$. This phenomenon can be minimized by reducing the dead gas volume of the reactor (see sec. 3.2.1), thus allowing to neglect the presence of a gas phase in the mass balances.

In this work, mixtures containing $\mathrm{CO}_{2}, \mathrm{NH}_{3}$, and $\mathrm{H}_{2} \mathrm{O}$ have been obtained by dissolving $\mathrm{BC}$ in aqueous ammonia solutions at different nominal ammonia concentrations in the solvent (up to $3 \% \mathrm{wt}$ ). While ammonium bicarbonate in water dissociates by forming equimolar mixtures of $\mathrm{CO}_{2}$ and $\mathrm{NH}_{3}$ (before speciation), the presence of an excess of ammonia shifts the ratio between the total nitrogen and carbon content, $\zeta$, to values greater than one, and significantly affects the speciation in solution.

The overall composition of such systems can be identified in the ternary diagram shown in Fig. 1; each point in the diagram corresponds to the overall mass fraction of equivalent $\mathrm{CO}_{2}, \mathrm{NH}_{3}$, and $\mathrm{H}_{2} \mathrm{O}$ (regardless of the liquid speciation and of the number of phases present at a given temperature and pressure). Additionally, the composition of the solid compounds (eqn (9)-(12)) are shown as black points. Mixtures characterized by a molar ratio $\zeta$ of one are represented by the isopleth (dashed black line) that connects the composition of the $\mathrm{BC}$ salt to the pure water vertex, while the other two isopleths drawn represent systems that are characterized by a molar ratio $\zeta$ of 1.3 and 2.0 .

As a consequence of the equilibria of eqn (1)-(8), when comparable amounts of nitrogen and carbon are present in the system $(\zeta \approx 1)$, the equilibria of eqn $(4)-(5)$ leads to

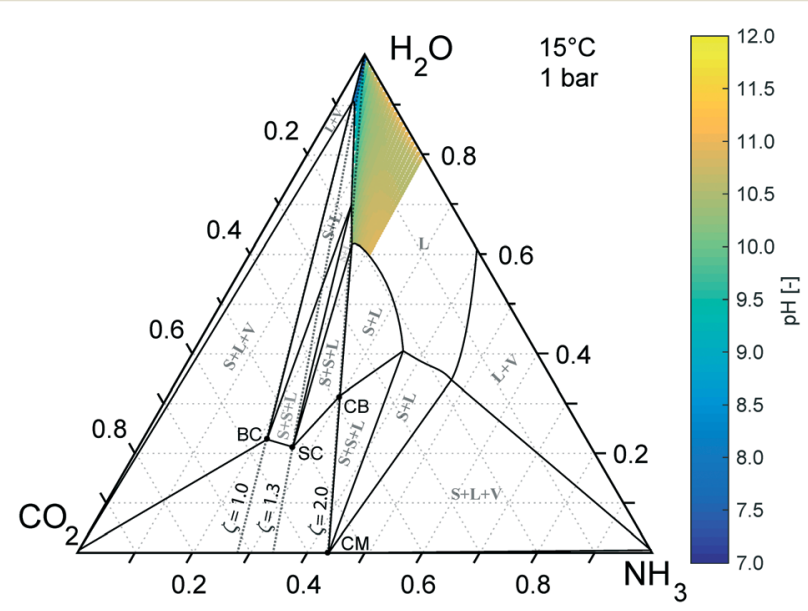

Fig. 1 Ternary phase diagram for the $\mathrm{CO}_{2}-\mathrm{NH}_{3}-\mathrm{H}_{2} \mathrm{O}$ system at $15^{\circ} \mathrm{C}$ and 1 bar obtained using the thermodynamic model proposed by Darde et al. ${ }^{6}$ The compositions are expressed in weight fractions and its construction and use have been described in detail elsewhere. ${ }^{18}$ The black dots $(\bullet)$ indicate the composition of the stable solid phases, namely ammonium bicarbonate (BC), ammonium carbonate monohydrate (CB), ammoniumsesquicarbonate ( $\mathrm{SC}$ ), and ammonium carbamate (CM). The dashed isopleths (black lines) refer to $\mathrm{CO}_{2}, \mathrm{NH}_{3}$, and $\mathrm{H}_{2} \mathrm{O}$ mixtures characterized by a constant ratio, $\zeta$, between the nitrogen and carbon species, while a colorcode is used to indicate the $\mathrm{pH}$ of the liquid phase calculated using the thermodynamic model proposed by Darde et al. ${ }^{6}$ mildly alkaline solutions in which the ammonium and bicarbonate ions are the main species present (see sec. 5.6). As the value of $\zeta$ becomes larger than one, the mixture becomes more and more alkaline (see the $\mathrm{pH}$ of the liquid phase shown in Fig. 1 using a color code) shifting the carbon speciation towards the carbonate and carbamate species.

\section{Experimental section}

\subsection{Materials}

Electrolyte solutions have been prepared using analytical grade chemicals purchased from Sigma-Aldrich (Buchs, Switzerland) and Milli-Q water (18.2 $\mathrm{M} \Omega \mathrm{cm}$ at $\left.25^{\circ} \mathrm{C}\right)$. Ammonium bicarbonate $\left(\mathrm{NH}_{4} \mathrm{HCO}_{3}\right.$, BioUltra, $\geq 99.5 \%$ pure), ammonium chloride $\left(\mathrm{NH}_{4} \mathrm{Cl}\right.$, BioUltra, $\geq 99.5 \%$ pure), potassium bicarbonate $\left(\mathrm{KHCO}_{3}\right.$, BioUltra, $\geq 99.5 \%$ pure $)$, and potassium carbonate $\left(\mathrm{K}_{2} \mathrm{CO}_{3}\right.$, BioUltra, $\geq 99 \%$ pure $)$ have been used without further purification.

The formation of potassium carbonate hydrates has been minimized by exploiting a drying step of the raw material at $100{ }^{\circ} \mathrm{C}$ under vacuum for a period of about 5 hours.

Ammonia solutions have been prepared by diluting commercial ammonium hydroxide solutions (Sigma-Aldrich, puriss. p.a., reag. ISO, reag. Ph. Eur. 25\% wt).

\subsection{Experimental setup and analytical methods}

3.2.1 Experimental setup. The equilibrium $\mathrm{CO}_{2}$ partial pressure of aqueous solutions of $\mathrm{NH}_{4} \mathrm{HCO}_{3}(\mathrm{aq})$ and $\mathrm{KHCO}_{3}(\mathrm{aq})$ exceeds by far the atmospheric pressure in the range of salt conditions explored in this work, eventually leading to a substantial material loss due to solute evaporation. The problem has been overcome by using a jacketed sealed vessel described in detail elsewhere ${ }^{9}$ that allows to maintain samples under their own vapor pressure, thus minimizing $\mathrm{CO}_{2}$ or $\mathrm{NH}_{3}$ losses from the liquid phase. In our experimental setup, the evaporation of $\mathrm{CO}_{2}, \mathrm{NH}_{3}$, and $\mathrm{H}_{2} \mathrm{O}$ to the vapour phase, consisting mainly of inert air, has been minimized by almost completely filling the reactor with the liquid during operation. The vessel's maximum operating pressure has been set to 5 bar and an impeller speed of 400 RPM has ensured adequate mixing. The process temperature control has been performed by means of a CC230 thermostat (Huber, Germany) connected to a Pt-100 probe immersed in the liquid phase of the reactor acquiring data at a frequency of $30 \mathrm{~s}^{-1}$.

The immersion probes of the monitoring tools such as the ATRFTIR and FBRM have been connected to the reactor by means of custom-made pressure connectors installed in the lid of the vessel (the interested reader is referred to the ESI $\dagger$ for an illustration of the experimental setup).

3.2.2 Analytical methods. The preparation of electrolyte solutions of inorganic salts used in this work has been carried out with a PG8001 analytical balance (Mettler-Toledo, Switzerland). The balance readability and maximum capacity are 0.1 $\mathrm{g}$ and $8.1 \mathrm{~kg}$, respectively; and the estimated accuracy of the static measurements is $\pm 0.23 \mathrm{~g}$. 
The concentration of commercial ammonium hydroxide solutions has been measured by acid-base titration using a 702 SM Titrino (METROHOM, Switzerland) and a $1 \mathrm{M} \mathrm{HCl} \mathrm{so-}$ lution as titrant.

3.2.3 Preparation of aqueous Ammonia solutions of ammonium bicarbonate. Aqueous ammonia solutions of BC have been prepared by dissolving specific amounts of ammonium bicarbonate in aqueous solution containing ammonia at the nominal concentration of 0,2 , and $3 \% \mathrm{wt}$, respectively. Since ammonium bicarbonate represents the only source of carbon in the system, the overall carbon and nitrogen balances for the liquid phase can be written as follows:

$$
\begin{gathered}
m_{\mathrm{C}, \mathrm{OL}}^{(\mathrm{l})}=m_{\mathrm{BC}}^{(\mathrm{l})}=m_{\mathrm{CO}_{2}}+m_{\mathrm{HCO}_{3}{ }^{-}}+m_{\mathrm{CO}_{3}{ }^{2-}}+m_{\mathrm{NH}_{2} \mathrm{COO}^{-}} \\
m_{\mathrm{N}, \mathrm{OL}}^{(1)}=m_{\mathrm{BC}}^{(1)}+m_{\mathrm{NH}_{3}}^{\circ}=m_{\mathrm{NH}_{3}}+m_{\mathrm{NH}_{4}{ }^{+}}+m_{\mathrm{NH}_{2} \mathrm{COO}^{-}}
\end{gathered}
$$

where $m_{\mathrm{C}, \mathrm{OL}}^{(\mathrm{l})}$ and $m_{\mathrm{N}, \mathrm{OL}}^{(\mathrm{l})}$ are the overall carbon and nitrogen concentration in the liquid phase, $m_{\mathrm{NH}_{3}}^{\circ}$ is the nominal concentration of ammonia in the initial solution (that plays the role of solvent for $\mathrm{BC}$ ), and $m_{\mathrm{BC}}^{(1)}$ is the overall concentration of ammonium bicarbonate in the liquid phase.

\subsection{In situ characterization techniques}

3.3.1 ATR-FTIR spectroscopy. ATR-FTIR spectroscopy has been applied to monitor the liquid phase concentration. Due to its low penetration depth, typically $2-3 \mu \mathrm{m}$, the ATR probe allows exclusively for liquid-phase monitoring also in the presence of a suspended solid phase. Samples have been collected using a ReactIR 45 m system (Mettler-Toledo, Switzerland), equipped with a $1.6 \mathrm{~cm}$ DiComp immersion probe and a 6 internal reflections diamond ATR crystal. The number of spectra have been collected in the $800-3000 \mathrm{~cm}^{-1}$ region with a wavenumber resolution of $4 \mathrm{~cm}^{-1}$ and averaged over 256 scans using an exposure time of $1 \mathrm{~min}$. The ATR-FTIR background signal has been collected in air, at ambient conditions, before every experiment.

3.3.2 Focused beam reflectance measurements. The device used for focused beam reflectance measurements (FBRM) allows for in situ determination of the chord length distribution (CLD) of suspended particles. In this work, a laboratory-scale FBRM device (Lasentec, Redmond, WA) has been used to detect the onset of particle formation during the ATR-FTIR calibration measurements and to monitor the complete dissolution of particles during BC solubility measurements in aqueous ammonia solutions. ${ }^{19}$ A 1 min measurement duration has been used for all FBRM measurement at a laser speed of $2 \mathrm{~ms}^{-1}$.

\subsection{IR peaks indentification}

ATR-FTIR spectroscopic analyses of aqueous solutions are challenging due to the strong water absorption over the entire midinfrared spectral region. Nevertheless, characteristic and well distinct IR-active bending modes of the species investigated in this work, i.e. $\mathrm{NH}_{4}{ }^{+}, \mathrm{NH}_{3}(\mathrm{aq}), \mathrm{CO}_{2}(\mathrm{aq}), \mathrm{HCO}_{3}{ }^{-}, \mathrm{CO}_{3}{ }^{2-}$, and
$\mathrm{NH}_{2} \mathrm{COO}^{-}$are observable in the spectrum of aqueous solutions containing $\mathrm{CO}_{2}$ and $\mathrm{NH}_{3}$ (ref. 10, 11 and 25) (see Table 1). The first step towards the resolution of such mixtures is represented by the isolation of the characteristic IR modes of each individual component. Then, a set of ATR-FTIR standards of the solute of interest can be prepared for calibration purposes.

Binary subsystems consisting of an inorganic salt and water in which the ionic species of interest dissociate completely with negligible speciation have therefore been selected. It has to be acknowledged that, due to the electrolytic nature of the solutes, the measurement of the IR spectrum necessarily embeds the absorbance of the solvent that can be removed during post-processing. ${ }^{26}$ In this work the subsystems $\mathrm{NH}_{4} \mathrm{Cl}(\mathrm{aq})$, $\mathrm{KHCO}_{3}(\mathrm{aq}), \mathrm{K}_{2} \mathrm{CO}_{3}(\mathrm{aq})$, and $\mathrm{NH}_{3}(\mathrm{aq})$ have been used to isolate the characteristic peaks of the ammonium, bicarbonate, carbonate ions, and ammonia respectively. ${ }^{11}$ This was possible thanks to the negligible extent of speciation of the single components within each subsystem. The presence of spectator ions such as $\mathrm{K}^{+}$and $\mathrm{Cl}^{-}$is accounted for in the electroneutrality condition and does not affect the relevant dissociation equilibria. Moreover, their effect on the absorbance of the solute of interest has not been significant in the range of concentrations investigated. ${ }^{27}$ ATR-FTIR polythermal measurements ${ }^{12}$ have been performed using the aforementioned subsystems in the thermostated, stirred and sealed vessel described in section 3.2.1. The range of temperatures and concentrations selected for the different subsystems is representative of the range of equivalent $\mathrm{CO}_{2}$ and $\mathrm{NH}_{3}$ concentrations investigated in this study and it is reported in Table 2. Samples of pure water, in the same temperature range, have also been collected for background subtraction.

The dissolution of $\mathrm{KHCO}_{3}$ in aqueous solution leads to a slightly alkaline environment in a wide range of salt concentrations. ${ }^{28}$ The formation of $\mathrm{CO}_{3}{ }^{2-}$ and $\mathrm{CO}_{2}(\mathrm{aq})$ according to the equilibria of eqn (5)-(7) occurs as well, and a spontaneous depletion of $\mathrm{HCO}_{3}{ }^{-}$in the liquid phase, albeit minimal, is expected until the vapor pressure of $\mathrm{CO}_{2}$ in the sealed reactor reaches the equilibrium partial pressure of $\mathrm{CO}_{2}(\mathrm{aq})$. Because of these phenomena, the analytical concentration of

Table 1 Main infrared band assignments of the species present in the $\mathrm{CO}_{2}-\mathrm{NH}_{3}-\mathrm{H}_{2} \mathrm{O}$ system. The symbols $v, v_{\mathrm{a}}$ and $\delta$ indicate the stretching mode, the asymmetric stretching mode, and the bending mode of the relevant molecules, respectively

\begin{tabular}{lll}
\hline Species & Band position $\left[\mathrm{cm}^{-1}\right]$ & Assignment \\
\hline $\mathrm{H}_{2} \mathrm{O}$ & 1640 & $\delta\left(\mathrm{H}_{2} \mathrm{O}\right)^{20}$ \\
$\mathrm{CO}_{2}(\mathrm{aq})$ & 2343 & $v_{\mathrm{a}}\left(\mathrm{CO}_{2}\right)^{20}$ \\
$\mathrm{NH}_{3}(\mathrm{aq})$ & 1111 & $\delta\left(\mathrm{NH}_{3}\right)^{20}$ \\
$\mathrm{NH}_{4}{ }^{+}$ & 1458 & $\delta(-\mathrm{NH})^{20}$ \\
$\mathrm{CO}_{3}{ }^{2-}$ & 1395 & $v_{\mathrm{a}}(-\mathrm{CO})^{21}$ \\
$\mathrm{NH}_{2} \mathrm{COO}^{-}$ & 1120 & $v(-\mathrm{CN})^{11,22,23}$ \\
& 1413 & $v(-\mathrm{CN})^{11,24}$ \\
& 1545 & $\delta(-\mathrm{N}-\mathrm{H})^{11,22}$ \\
$\mathrm{HCO}_{3}{ }^{-}{ }^{-}$ref. 21) & 1005 & $v_{\mathrm{a}}(-\mathrm{C}-\mathrm{OH})$ \\
& 1300 & $\delta(-\mathrm{C}-\mathrm{OH})$ \\
& 1365 & $v(-\mathrm{C}-\mathrm{O})$ \\
& 1650 & $v_{\mathrm{a}}(-\mathrm{C}-\mathrm{O})$
\end{tabular}


Table 2 Set of standard solute concentrations and temperatures used for the species-wise ATR-FTIR calibration models

\begin{tabular}{|c|c|c|c|c|c|c|c|c|}
\hline $\begin{array}{l}\text { Compound } \\
\text { Sample no. }\end{array}$ & \multicolumn{4}{|c|}{$\underline{\text { Concentration }\left[\mathrm{mol} \mathrm{kg}_{\mathrm{w}}{ }^{-1}\right]}$} & \multicolumn{4}{|c|}{ Temperature $\left[{ }^{\circ} \mathrm{C}\right]$} \\
\hline $\mathrm{NH}_{4} \mathrm{HCO}_{3}(\mathrm{aq})\left(m_{\mathrm{NH}_{3}}^{\circ}=0 \mathrm{~m}\right)$ & 1.76 & 2.02 & 2.31 & 2.64 & $5-25$ & $10^{b}-25$ & $10^{b}-25$ & $16^{b}-25$ \\
\hline $\mathrm{NH}_{4} \mathrm{HCO}_{3}(\mathrm{aq})\left(m_{\mathrm{NH}_{3}}^{\circ}=1.2 \mathrm{~m}\right)$ & 2.64 & 2.89 & 3.05 & 3.17 & $5-25$ & $8^{b}-25$ & $12^{b}-25$ & $14^{b}-25$ \\
\hline $\mathrm{NH}_{4} \mathrm{HCO}_{3}(\mathrm{aq})\left(m_{\mathrm{NH}_{3}}^{\circ}=1.8 \mathrm{~m}\right)$ & 3.06 & 3.27 & 3.42 & 3.53 & $5-25$ & $6^{b}-25$ & $8^{b}-25$ & $13^{b}-25$ \\
\hline $\mathrm{NH}_{4} \mathrm{Cl}(\mathrm{aq})$ & 1.71 & 2.14 & 2.48 & 2.83 & $5-25$ & & & \\
\hline $\mathrm{NH}_{3}(\mathrm{aq})$ & $0.61^{a}$ & 1.25 & 1.93 & $\mathrm{n} / \mathrm{a}$ & $5-25$ & & & \\
\hline
\end{tabular}

${ }^{a}$ ATR-FTIR detection limit for the $\mathrm{NH}_{3}(\mathrm{aq}) .{ }^{b}$ Temperature value corresponding to the onset of primary nucleation (see the ESI for further information.

the $\mathrm{KHCO}_{3}(\mathrm{aq})$ standards has been corrected accounting for the presence of $\mathrm{CO}_{3}{ }^{2-}$ and $\mathrm{CO}_{2}(\mathrm{aq})$ in solution using the geochemical equilibrium software package EQ3/6 v. 8.0. ${ }^{29}$ The extent of speciation of the $\mathrm{HCO}_{3}{ }^{-}$ion has been found anyhow to be less than $5 \%$ wt. Similarly, the speciation of $\mathrm{CO}_{3}{ }^{2-}$ in the standard samples of $\mathrm{K}_{2} \mathrm{CO}_{3}(\mathrm{aq})$ has not been observed given the detection limit of the ATR-FTIR spectrometer.

Due to the acidic nature of $\mathrm{NH}_{4} \mathrm{Cl}(\mathrm{aq})$ solutions, the speciation of the $\mathrm{NH}_{4}{ }^{+}$into $\mathrm{NH}_{3}(\mathrm{aq})$ is virtually absent, thus facilitating the isolation of the characteristic $\mathrm{NH}_{4}{ }^{+}$peak. Conversely, the alkaline environment of aqueous ammonia solutions inhibits the hydrolysis of $\mathrm{NH}_{3}(\mathrm{aq})$ into $\mathrm{NH}_{4}{ }^{+}$, thus allowing the extraction of the $\mathrm{NH}_{3}(\mathrm{aq})$ peak from the infrared spectrum.

The asymmetric $\mathrm{C}=\mathrm{O}$ stretching band of the $\mathrm{CO}_{2}$ located at $2343 \mathrm{~cm}^{-1}$ in the infrared spectrum does not overlap with the spectrum of any other species in solution and has good analytical potential for the determination of the carbon dioxide concentration in water 30 (see the ESI $\dagger$ for further information). However the extent of $\mathrm{CO}_{2}(\mathrm{aq})$ formation has been found negligible in the range of operating conditions explored (see sec. 5.6), and its concentration has been deter- mined by using a mass balance on the liquid phase instead of developing a dedicated calibration model.

The formation of carbamate ions $\left(\mathrm{NH}_{2} \mathrm{COO}^{-}\right)$due to the reaction of eqn (8) yields several characteristic peaks associated to this species located respectively at $1545 \mathrm{~cm}^{-1}$, at $\sim 1400$ $\mathrm{cm}^{-1}$, and at $1120 \mathrm{~cm}^{-1}$ in the infrared spectrum ${ }^{10,11,23}$ (see Fig. $2 \mathrm{~b}$ ). The segregation of these peaks is complicated by the pronounced overlap with the spectrum of the other species; the extent of speciation, in general, does not allow for a direct measurement of the actual concentration of the carbamate ion. In light of these considerations, two of the three characteristic peaks of the carbamate ion have been modeled, after subtraction of the spectrum of the solvent, using Gaussian functions such as:

$$
a(\tilde{v})=\exp \left[-\frac{(\tilde{v}-\mu)}{\sigma}\right]^{2}
$$

in which the location of each peak, $\mu$, has been set based on the available literature data ${ }^{10,11}$ and its broadness, $\sigma$, has been chosen by appling an optimization procedure discussed in sec.

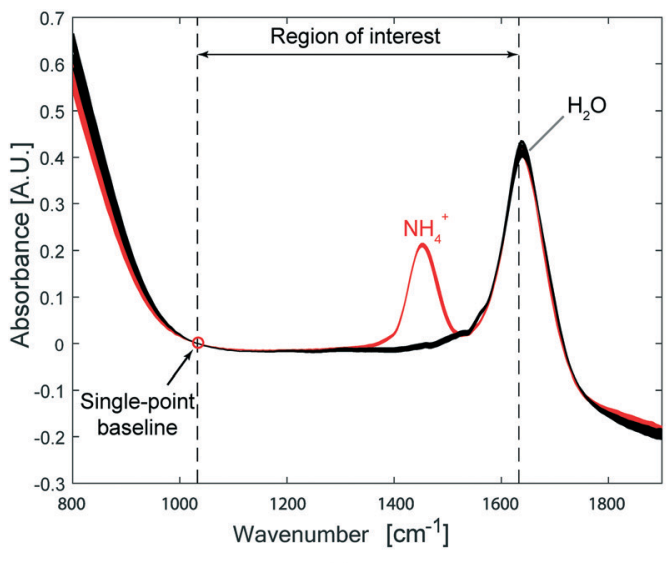

(a)

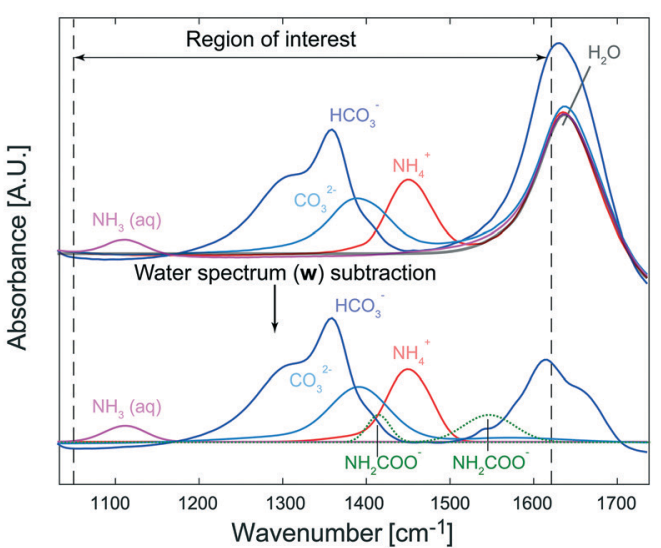

(b)

Fig. 2 (a) Exemplary cases of single-point baseline correction (red circle) applied to all the IR spectra collected in this study (see sec. 3.5). The examples refer to the IR spectrum of the $\mathrm{NH}_{4}{ }^{+}$ion (red curves) and to the spectrum of $\mathrm{H}_{2} \mathrm{O}$ (black curves), respectively. The region of interest of the infrared spectrum of this study is indicated by dashed lines. (b) Examples of solvent (water) background subtraction from the measured spectrum of different ionic species in aqueous solution, i.e. $\mathrm{NH}_{3}(\mathrm{aq}), \mathrm{NH}_{4}{ }^{+}, \mathrm{HCO}_{3}{ }^{-}$, and $\mathrm{CO}_{3}{ }^{2-}$. Note that the characteristic bands of the $\mathrm{NH}_{2} \mathrm{COO}^{-}$(green spectra) have been modeled, net of the spectrum of the solvent, as Gaussian functions using eqn (18) (see sec. 3.4 for further details). 
5.6.1. In eqn (18), $a$ is the infrared absorbance function of the wavenumber $\tilde{v}$, and the values of $m$ and $s$ are respectively equal to $1545 \mathrm{~cm}^{-1}$ and $1413 \mathrm{~cm}^{-1}$, and $43.1 \mathrm{~cm}^{-1}$ and $19.2 \mathrm{~cm}^{-1}$ for the two modeled peaks of the carbamate ion. The carbamate band located at $1120 \mathrm{~cm}^{-1}$, characterized by a much lower absorptivity compared to the other characteristic peaks, ${ }^{10,11}$ has been neglected from the modeling procedure without significantly affecting the representation of the system.

\subsection{Preprocessing techniques}

As illustrated in Fig. 2a, the ATR-FTIR pre-processing technique for all the raw IR spectra collected consisted of a single-point baseline correction applied at $1033 \mathrm{~cm}^{-1}$ of the spectrum (red circle), The technique has been developed in our laboratory and implemented in MATLAB. The use of this constant baseline correction is effective in removing the background signal of the solvent (water) that appears almost as an off-set over the range of wavenumbers of interest, i.e. $1033-1610 \mathrm{~cm}^{-1}$. Fig. $2 \mathrm{~b}$ shows how the IR spectrum of each pure component has been isolated from the background signal of the solvent by subtracting the baseline-corrected spectrum of water from the measured spectrum of the electrolytes in aqueous solution at the relevant temperature (see below for the details).

\section{Modeling}

\subsection{Model equations}

From a mathematical point of view the infrared absorbance of a multicomponent liquid mixture of given composition is a continuous function $a(\tilde{v}, T)$ defined on the wavenumber, $\tilde{v}$, and temperature, $T$, domains. However, from a practical point of view, due to the instrument finite resolution, the measured spectrum can be described as a vector of data points recorded at $m$ discrete wavenumber values, i.e. $\mathbf{a}(\tilde{v}, T)=$ $\left[a\left(\tilde{v}_{1}, T\right), \ldots, a\left(\tilde{v}_{\mathrm{m}}, T\right)\right]^{T}$, at a given temperature.

This work uses a multivariate classical least squares method $^{26,31}$ to model the multicomponent spectrum of mixtures of $\mathrm{CO}_{2}, \mathrm{NH}_{3}$, and $\mathrm{H}_{2} \mathrm{O}$. It assumes the Beer-Lambert law for the spectrum of each pure component, $\mathbf{a}_{i}$, to be valid and the effect of intermolecular interactions on the IR spectrum to be negligible:

$$
a_{i}(\tilde{v})=q_{i} c_{i}
$$

In eqn (19), $a_{i}, c_{i}$, and $q_{i}$ are the absorbance, the concentration, and the absorptivity respectively of the $i$-th component in solution.

Additionally, the method requires a calibration step that relates the spectra of a given set of standards to their known concentration.

\subsection{Classical least squares method}

The linear model of an ATR-FTIR spectrum discretized over $m$ wavenumbers, the vector a, which embeds $n$ overlapping components is, at a given temperature $T$ :

$$
\mathbf{a}=\mathbf{a}^{*}+\mathbf{w}=\sum_{i=2}^{n} k_{i} \overline{\mathbf{a}}_{i}^{*}+\mathbf{w}+\varepsilon
$$

where the index $i$ associated with the solvent (water) is 1 ; the vector $\mathbf{a}^{*}(T)$ is the spectrum of the mixture after subtracting the contribution of the solvent, i.e. the vector $\mathbf{w}(T) ; k_{i}$ is the CLS weight parameter relative to the $i$-th component; the vector $\overline{\mathbf{a}}_{i}^{*}$ is the CLS reference spectrum of the $i$-th component; and the vector $\varepsilon$ is the residual error of the model. The CLS reference spectra are defined as the spectra of the standards at the lowest concentration value of the calibration set reported in Table 2. Since $m \gg n$, the optimal set of parameters, $\hat{\mathbf{k}}=\left[\hat{k}_{2}, \ldots\right.$, $\left.\hat{k}_{n}\right]^{T}$, that minimizes the residual error of eqn (20) can be computed by solving the following optimization problem:

$$
\underset{\mathbf{k}}{\operatorname{minimize}}\left\|\mathbf{a}^{*}-\mathbf{A} \mathbf{k}\right\|_{2}
$$

where the CLS reference spectra of the pure components (solutes) are collected column-wise into the matrix A. The set of reference spectra also accounts for the temperature dependence of the spectrum of each species in solution:

$$
\mathbf{A}(T)=\left[\overline{\mathbf{a}}_{2}^{*}(T), \ldots, \overline{\mathbf{a}}_{n}^{*}(T)\right]
$$

Therefore, the vector estimator $\hat{\mathbf{k}}$ (with $[n-1]$ elements) of the unknown parameters is calculated as: ${ }^{32}$

$$
\hat{\mathbf{k}}=\left(\mathbf{A}^{\mathrm{T}} \mathbf{A}\right)^{-1} \mathbf{A}^{\mathrm{T}} \mathbf{a}^{*}
$$

Then, the set of optimal parameters allows to estimate the spectrum of the mixture, â, as:

$$
\hat{\mathbf{a}}=\mathbf{A} \hat{\mathbf{k}}+\mathbf{w}
$$

Eventually, the concentration estimate of the $i$-th solute, $\hat{\mathrm{c}}_{i}$, can be calculated using a calibration model $f_{i}$ that relates its estimated IR spectrum, the vector $\hat{\mathbf{a}}_{i}=\hat{k}_{i} \overline{\mathbf{a}}_{i}^{*}+\mathbf{w}$, to its concentration.

$$
\hat{\mathrm{c}}_{i}=f_{i}\left(\hat{\mathrm{a}}_{i}\right) \quad i=2, \ldots, n
$$

The CLS algorithm is illustrated in Fig. 3, while the derivation of the calibration models is discussed, in detail, in sec. 5.3.

\section{Results and discussion}

The following sections address important aspects related to the application of the CLS method to real mixtures containing $\mathrm{CO}_{2}$, $\mathrm{NH}_{3}$, and $\mathrm{H}_{2} \mathrm{O}$. At first, the validity of the Beer-Lambert law and the capability of the CLS model to resolve complex overlapping spectra are investigated. Then, different calibration approaches are compared in terms of accuracy and reliability of the concentration estimates. Against this background, the speciation of aqueous ammonia solutions of $\mathrm{BC}$ have been assessed, investigating, in particular, the effect of a stoichiometric excess of ammonia, on the equilibria established in solution. Additionally, the solid-liquid equilibrium of 
ammonium bicarbonate has been characterized and modeled, thus establishing a rigorous thermodynamic framework for the estimation of the solution supersaturation.

\subsection{Validity of the Beer-Lambert law}

The validity of the Beer-Lambert law for the pure components, in the range of concentrations explored in this work, is a prerequisite for the application of the CLS method to the spectrum of a mixture of unknown composition. In this regard, Fig. 4 shows the sets of normalized (and overlapping) spectra of the pure species in aqueous solution corresponding to the different concentrations used for calibration (see Table 2). The overlapping of spectra is indicative of systems for which the Beer-Lambert law applies, i.e. a linear relationship between the absorbance and the concentration. However, in this system deviations from the linear behavior can be noticed especially for the $\mathrm{NH}_{4}{ }^{+}$and the $\mathrm{HCO}_{3}{ }^{-}$ions. More in detail, Fig. 4a shows a slight shift of the absorption bands of $\mathrm{NH}_{4}^{+}$, while in Fig. $4 \mathrm{~b}$ a certain absorbance variability is noticeable in the proximity of the lower shoulder of the $\mathrm{HCO}_{3}{ }^{-}$peak; deviations in the wavenumber range between 1350-1450 $\mathrm{cm}^{-1}$ may be attributed to the concomitant presence of $\mathrm{CO}_{3}{ }^{2-}$ in solution, while no significant deviations could be reported in the case of $\mathrm{CO}_{3}{ }^{2-}$ and of $\mathrm{NH}_{3}(\mathrm{aq})$.

\subsection{Effect of temperature on the spectrum of a pure solute}

As described in section 4, the proposed modeling approach accounts also for the temperature dependence of the spectrum of the unknown mixture, in order to improve the accuracy of the concentration estimates. To prove the relevance of this effect, Fig. 5 shows a cursory analysis on the temperature behavior of the maximum peak height and position of the characteristic IR bands of the pure species. As a general trend, the maximum peak heights decrease linearly with increasing values of temperature, for all the species, at fixed concentration values. This phenomenon is probably due to the weakening of the $\mathrm{H}$-bonds between water and solutes with increasing temperature; ${ }^{16}$ it is distinct in the case of the $\mathrm{CO}_{3}{ }^{2-}$ spectrum, while the decreasing trend is negligible for the remaining species. The peak position of the $\mathrm{NH}_{4}^{+}$ion slightly shifts to lower values with increasing temperature as shown in Fig. 5a.

\subsection{ATR-FTIR calibration methods}

Several functional forms for the general calibration model presented in eqn (25) have been suggested and analyzed in order to identify the most accurate method for the estimation of the solute concentrations. The screening carried out in this study considered calibration models based on the maximum absorbance peak height (model I), on the maximum absorbance peak area (model II), and on a partial least squares regression (PLSR) of spectral data (model III). The root mean squared error of prediction, RMSE, has been used to compare the performance of the different calibration models of each component as follows:

$$
\mathrm{RMSE}_{i}=\sqrt{E\left[\left(\hat{\mathbf{c}}_{i}^{\circ}-\mathbf{c}_{i}^{\circ}\right)\right]} \quad i=2, \ldots n
$$

where $E$ is the mean operator; $\hat{\mathbf{c}}_{i}^{\circ}$ and $\mathbf{c}_{i}^{\circ}$ are respectively the vector of concentration estimates of the standards of the $i$-th component, and the vector of the relative standard concentrations.

Before discussing the details of each method, it is useful to introduce the operator $S$ that extracts the specific features of a generic IR spectrum, s, used by the different calibration methods:

$$
S(s, T)= \begin{cases}\max s(T) & \text { Peak Height Method } \\ \sum_{j=a}^{b} s\left(\tilde{v}_{j}, T\right) \Delta \tilde{v} & \text { Peak Area Method } \\ {\left[s\left(\tilde{v}_{a}, T\right), \ldots, s\left(\tilde{v}_{b}, T\right)\right]^{T}} & \text { PLSR Method }\end{cases}
$$

where $\mathrm{s}\left(\tilde{v}_{j}, T\right)$ is the absorbance at a specific wavenumber $\tilde{v}_{j}$ and temperature $T ; \Delta \tilde{v}_{j}$ is the fixed interval between two discretized wavenumbers; and $[a, b]$ is a generic range of wavenumbers. Details on the maximum peak positions and wavenumber ranges adopted for each component are reported in Table 3 .

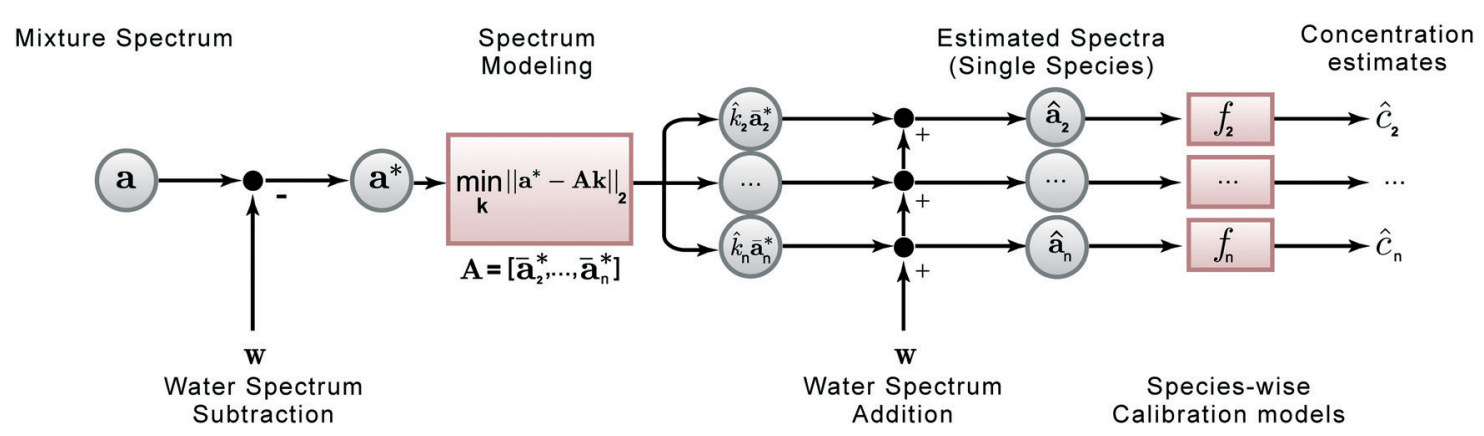

Fig. 3 Graphical representation of the algorithm used to resolve overlapping ATR-FTIR bands of aqueous species in solution. The algorithm includes a modeling step of the spectrum of the mixture represented by a classical least squares (CLS) method, and uses calibration functions (eqn (25)) for the computation of the concentration estimates. 


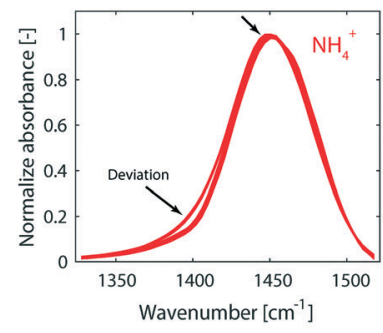

(a)

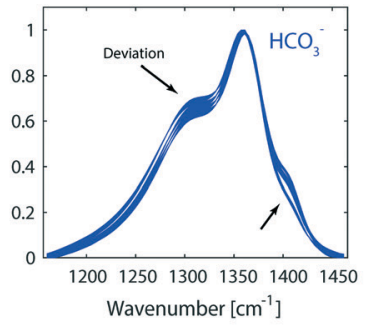

(b)

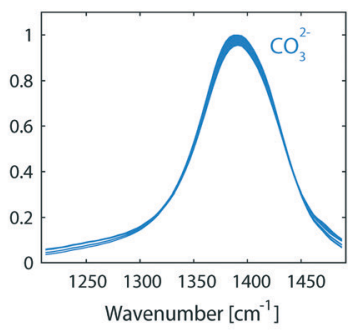

(c)

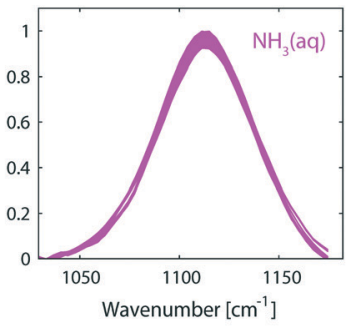

(d)

Fig. 4 Set of normalized and overlapped spectra of pure electrolyte species in aqueous solution in the concentration and temperature ranges investigated in this work (see Table 2). The main deviations are indicated by arrows. (a-d) IR spectra relative to the $\mathrm{NH}_{4}{ }^{+}, \mathrm{HCO}_{3}{ }^{-}, \mathrm{CO}_{3}{ }^{2-}$, and $\mathrm{NH}_{3}(\mathrm{aq})$ species respectively.

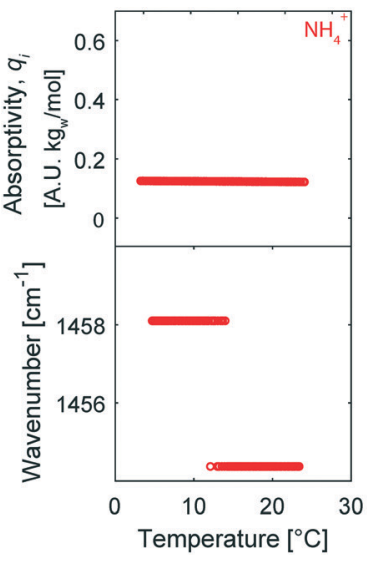

(a)

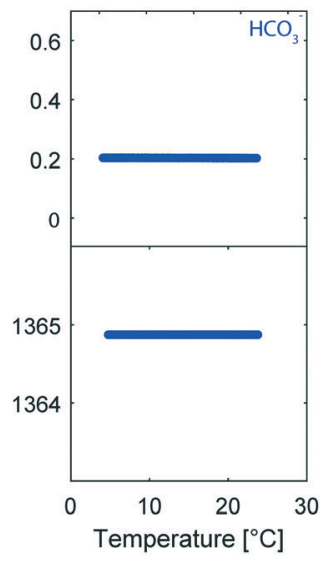

(b)

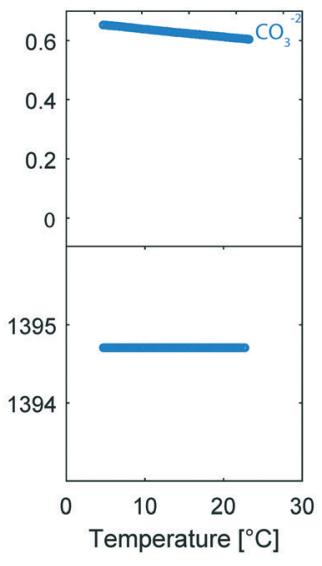

(c)

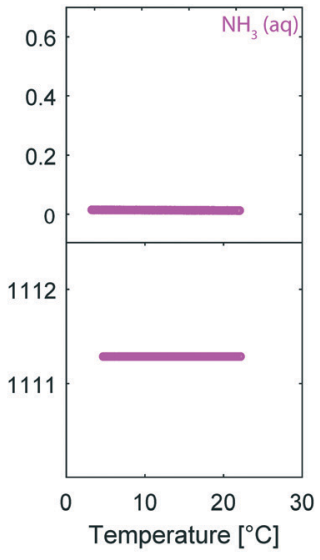

(d)

Fig. 5 Measured absorptivities and positions of the maximum IR peaks of the solutes as a function of temperature, at constant solute concentration. The analyses are relative to the IR bands corresponding to the minimum value of the standard concentrations of $\mathrm{NH}_{4} \mathrm{Cl}(\mathrm{aq}), \mathrm{KHCO}_{3}(\mathrm{aq}), \mathrm{K}_{2} \mathrm{CO}_{3}(\mathrm{aq})$, and $\mathrm{NH}_{3}\left(\right.$ aq) reported in Table 2. The discontinuity in the maximum IR peak position of the $\mathrm{NH}_{4}{ }^{+}$ion is due to the finite resolution of the IR spectrum recorded. (a)-(d) Refer to the ammonium ion, the bicarbonate ion, the carbonate ion, and the aqueous ammonia, respectively.

5.3.1 ATR-FTIR calibration based on maximum peak height or on maximum peak area. For each pure component, a set of $\left(N_{i} \cdot M\right)$ reference spectra of the pure electrolytes has been used for the regression of a linear calibration model based on two independent variables: either the maximum peak height or the maximum peak area, and the temperature

Table 3 Statistics of the different calibration models for the concentration estimates of species in solution. An asterisk $(*)$ denotes that the value refers to a 10 -fold cross validation RMSE for the BC concentration ${ }^{12}$

\begin{tabular}{|c|c|c|c|c|c|}
\hline Species & Method & Wavenumber $\left[\mathrm{cm}^{-1}\right]$ & $r[-]$ & RMSE $\left[\mathrm{mol} \mathrm{kg}_{\mathrm{w}}^{-1}\right]$ & $R^{2}[-]$ \\
\hline & Maximum peak height & $\tilde{v}=1458$ & $\mathrm{n} / \mathrm{a}$ & 0.030 & 0.9918 \\
\hline \multirow[t]{3}{*}{$\mathrm{HCO}_{3}^{-}$} & Peak area & $1156 \leq \tilde{v} \leq 1466$ & $\mathrm{n} / \mathrm{a}$ & 0.1104 & 0.9990 \\
\hline & Maximum peak height & $\tilde{v}=1365$ & $\mathrm{n} / \mathrm{a}$ & 0.1042 & 0.9937 \\
\hline & PLSR & $1156 \leq \tilde{v} \leq 1466$ & 5 & 0.0317 & $\mathrm{n} / \mathrm{a}$ \\
\hline $\mathrm{CO}_{3}{ }^{2-}$ & Peak area & $1208 \leq \tilde{v} \leq 1492$ & $\mathrm{n} / \mathrm{a}$ & 0.0090 & 0.9974 \\
\hline \multirow[t]{3}{*}{$\mathrm{NH}_{3}$} & Peak area & $1033 \leq \tilde{v} \leq 1178$ & $\mathrm{n} / \mathrm{a}$ & 0.0898 & 0.9988 \\
\hline & Maximum peak height & $\tilde{v}=1111$ & $\mathrm{n} / \mathrm{a}$ & 0.0397 & 0.9976 \\
\hline & PLSR & $1033 \leq \tilde{v} \leq 1178$ & 6 & 0.0022 & $\mathrm{n} / \mathrm{a}$ \\
\hline $\mathrm{BC}(\mathrm{aq})$ & PLSR & $980 \leq \tilde{v} \leq 1036$ & 7 & $7.97 \times 10^{-5}(*)$ & 0.9999 \\
\hline $\mathrm{BC}\left(m_{\mathrm{NH}_{3}}^{\circ}=1.2 \mathrm{~m}\right)$ & PLSR & $980 \leq \tilde{v} \leq 1036$ & 10 & $0.0070(*)$ & 0.9982 \\
\hline
\end{tabular}


(see Fig. 6). We name such reference spectra $\mathbf{a}_{i, n, m^{\prime}}^{\circ}$, where $n=$ $1, \ldots, N_{i}$ and $m^{\prime}=1, \ldots, M$ are the reference concentration and the reference temperature indices, respectively. The estimate of the model parameters vector, $\hat{\mathbf{p}}_{i}$, is obtained by solving the multiple linear regression (MLR) problem defined by:

$$
\underset{\mathbf{p}_{i}}{\operatorname{minimize}}\left\|\mathbf{c}_{i}^{\circ}-\mathbf{X}_{i} \mathbf{p}_{i}\right\|_{2} \quad i=2, \ldots, n
$$

where the vector $\mathbf{p}_{i}=\left[p_{0, i}, p_{1, i}, p_{2, i}\right]^{\mathrm{T}}$ is the parameters vector, the matrix $\mathbf{X}_{i}$ contains a first column vector of ones to account for the intercept term $p_{0, i}$, a second column vector that stores the features of the reference spectra extracted by the operator $S$ according to the calibration method considered $\left(\left[S\left(\mathbf{a}_{i, 1,1}^{\circ}, T_{i, 1,1}\right), \ldots, S\left(\mathbf{a}_{i, N_{i}, M}^{\circ}, T_{i, N_{i}, M}\right)\right]^{T}\right)$, and a third column vector of measured temperatures, $\mathbf{T}_{i}$. For the sake of completeness, the sets of optimal parameters are reported in the ESI. $\dagger$

The good quality of the fitting is confirmed by the values of the coefficient of determination, $R^{2}$ (see Table 3 ). This is also indicative of the validity of the Beer-Lambert law in the range of operating conditions explored in this work.

Ultimately, the regressed models can be used to estimate the concentration of the $i$-th component as:

$$
\hat{c}_{i}=\hat{p}_{0, i}+\hat{p}_{1, i} S\left(\hat{\mathbf{a}}_{i}, T\right)+\hat{p}_{2, i} T \quad i=2, \ldots, n
$$

5.3.2 ATR-FTIR calibration based on PLS analysis. Contrary to the univariate calibration methods that correlate the solute concentration to specific peak heights or peak areas, a multivariate PLS model exploits a range of absorption bands characteristic of the solute to estimate its concentration. In this regard, the operator $S$ applied to a generic reference spectrum $\mathbf{a}_{i, n, m^{\prime}}^{\circ}$ yields a (row) vector of $k$ elements that represent the spectral absorbances in the range of wavenumbers considered (see Table 3). The matrix $\mathbf{S}_{i}=\left[S\left(\mathbf{a}_{i, 1,1}^{\circ}, T_{i, 1,1}\right)^{T}, \ldots, S\left(\mathbf{a}_{i, N_{i}, M}^{\circ}, T_{i, N_{i}, M}\right)^{T}\right]^{T}$ that contains the

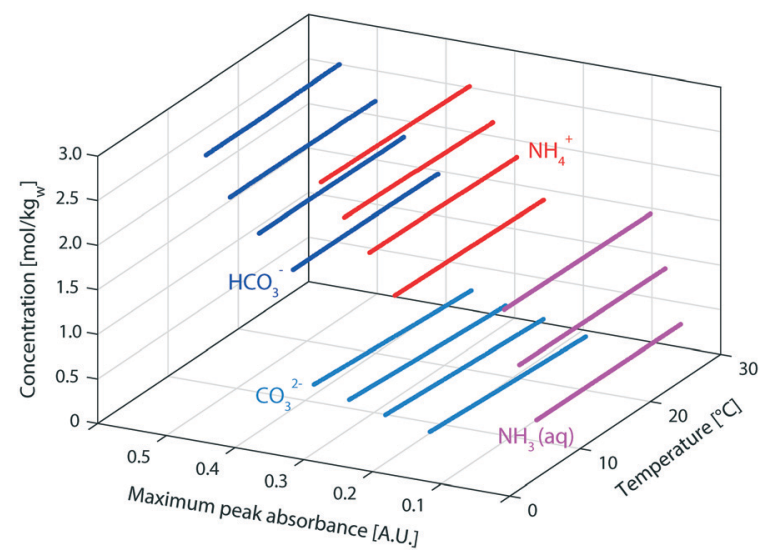

Fig. 6 ATR-FTIR calibrations based on the maximum peak height and temperature for the concentration estimate of the $\mathrm{HCO}_{3}^{-}, \mathrm{CO}_{3}{ }^{2-}$, $\mathrm{NH}_{4}{ }^{+}$, and $\mathrm{NH}_{3}$ (aq) respectively. processed reference spectra of the $i$-th component is projected onto a score matrix $\mathbf{K}_{i}$ (eqn (30)) by using a matrix of weights, $\mathbf{W}_{i}$, computed in such a way that the covariance between the colum vectors $\mathbf{k}_{i, j}$ ( $j$-th column of $\mathbf{K}_{i}$ ) and the vector of reference concentrations $\mathbf{c}_{i}^{\circ}$ is maximized: ${ }^{12}$

$$
\mathbf{K}_{i}=\mathbf{S}_{i} \mathbf{W}_{i}
$$

The method allows to reduce the collinearity of the raw spectral data and leads to a score matrix $\mathbf{K}_{i}$ that contains a set of linearly independent combinations of the original $k$ wavenumbers that still carry the relevant information about the spectra. Similarly to eqn (28), the PLS regressor vector $\mathbf{b}_{i}$ is estimated by solving the following minimization problem:

$$
\underset{\mathbf{b}_{i}}{\operatorname{minimize}}\left\|\mathbf{c}_{i}^{\circ}-\mathbf{K}_{i} \mathbf{b}_{i}\right\|_{2} \quad i=2, \ldots, n
$$

for which the least-square estimator of $\mathbf{b}_{i}$ is:

$$
\hat{\mathbf{b}}_{i}=\left(\mathbf{K}_{i}^{\mathrm{T}} \mathbf{K}_{i}\right)^{-1} \mathbf{K}_{i}^{\mathrm{T}} \mathbf{c}_{i}^{\circ}
$$

Finally, the PLSR model can be used to estimate the concentration of the $i$-th component as:

$$
\hat{c}_{i}=S\left(\hat{\mathbf{a}}_{i}, T\right)^{\mathrm{T}} \mathbf{W}_{i} \hat{\mathbf{b}}_{i}
$$

The optimal number of linearly independent combinations of the original $k$ wavenumbers (latent variables of the PLS model), $r$, has been chosen so as the root mean squared error of 10 -fold cross-validation, $\mathrm{RMSECV}_{10}$, of the PLS model is minimized ${ }^{12}$ (see Table 3).

5.3.3 Comparison of the ATR-FTIR calibration methods. Fig. 7 shows the comparison of the different calibration models in terms of RMSE. As expected, the most accurate and robust concentration estimates are those based on a multivariate PLS regression that has the ability of weighing absorbances that are highly predictive of the concentration of the different species. ${ }^{13}$ Among the PLSR models, the least accurate ones are those for the concentration prediction of the $\mathrm{HCO}_{3}{ }^{-}$and the $\mathrm{NH}_{4}{ }^{+}$ions. In fact, the ATR-FTIR bands of these species, as discussed in section 5.1, exhibit the largest deviations from linearity over the range of wavenumbers considered for the calibration.

In light of these considerations, this work adopts a set of multivariate PLS calibration models $f_{i}$ (eqn (25)) to estimate solute concentrations, unless explicitly stated otherwise.

\subsection{Model validation}

First, the predictive capability of the proposed CLS methodology has been assessed for the case of binary mixtures of known composition, namely $\mathrm{NH}_{4} \mathrm{Cl}(\mathrm{aq})$ and $\mathrm{KHCO}_{3}(\mathrm{aq})$. In detail, the validation exploits a set of in silico generated IR spectra of $\mathrm{NH}_{4} \mathrm{Cl}(\mathrm{aq})$ and $\mathrm{KHCO}_{3}(\mathrm{aq})$ obtained by combining the spectra of the pure standards, as well as a set of real 


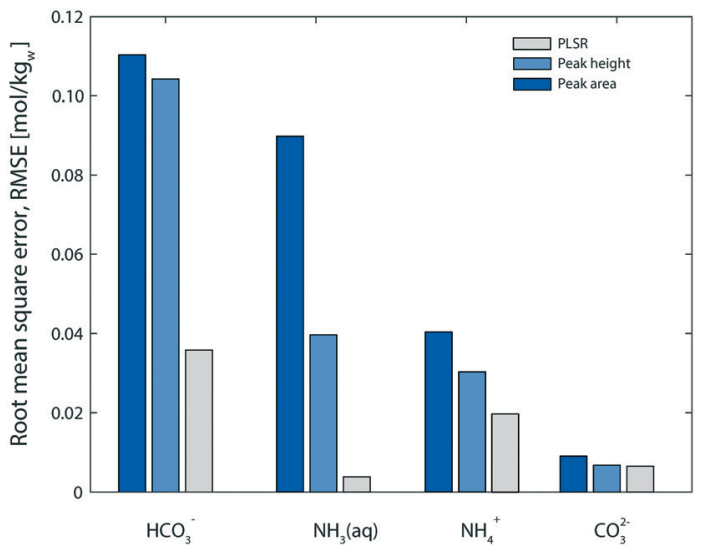

Fig. 7 Comparison of the root mean squared errors (RMSEs) of prediction of the concentration of solutes obtained using the different ATR-FTIR calibration methods discussed in sec. 5.3.

spectra of aqueous mixtures of $\mathrm{NH}_{4} \mathrm{Cl}(\mathrm{aq})$ and $\mathrm{KHCO}_{3}(\mathrm{aq})$, and of aqueous solutions of $\mathrm{NH}_{4} \mathrm{HCO}_{3}(\mathrm{BC})$. For the real mixtures ${ }^{13} \mathrm{C}$-NMR spectroscopic analyses ${ }^{33,34}$ (reported in the ESI $\dagger$ ) have been used to select the solutions that exhibit a low degree of speciation (e.g. absence of carbamate ion formation) to be included in the validation set. Then, the spectral data, both the simulated and experimental, has been processed using the CLS method proposed in sec. 4, and the resulting concentration estimates have been compared with the reference values. Fig. 8 shows that the absolute error of prediction for the $\mathrm{NH}_{4}{ }^{+}$and $\mathrm{HCO}_{3}{ }^{-}$ions in virtual binary mixtures (red and blue dots, respectively) is below $5 \%$. Similar results are obtained for real mixtures of $\mathrm{NH}_{4} \mathrm{Cl}(\mathrm{aq})$ and $\mathrm{KHCO}_{3}(\mathrm{aq})$ indicated by stars, and for aqueous solutions of $\mathrm{BC}$ indicated by triangles. The underprediction of the $\mathrm{HCO}_{3}{ }^{-}$ concentrations for the case of real mixtures may be attributed to the formation of $\mathrm{CO}_{2}(\mathrm{aq})$ and $\mathrm{CO}_{3}{ }^{2-}$ in solution.

An analysis on the accuracy of the concentration estimates for the case of mixtures of $\mathrm{CO}_{2}, \mathrm{NH}_{3}$, and $\mathrm{H}_{2} \mathrm{O}$ characterized by the formation of more than 2 main species cannot be directly performed due to the lack of information on the actual concentration of the species in solution. However, meaningful insights can be provided about the robustness of the CLS algorithm and on its capability of resolving the spectrum of mixtures containing more than 2 overlapping components. In this regard, fictitious quaternary spectra containing the overlapping peaks of $\mathrm{NH}_{4}{ }^{+}, \mathrm{HCO}_{3}{ }^{-}, \mathrm{CO}_{3}{ }^{2-}$, and $\mathrm{NH}_{3}(\mathrm{aq})$ have been simulated by combining the experimental spectral data of the pure standards. Then, the CLS methodology has been applied to the in silico generated spectral data.

Based on the outcome of the model, provided in the parity plots of Fig. 9, the CLS algorithm is capable of resolving effectively overlapping bands in the IR spectrum of the mixture with a maximum error in the concentration estimates of $\pm 10 \%$. These errors stem primarily from the difference that exists between the set of reference spectra a used by the algorithm and the fitted spectra of the standards, $\mathbf{a}^{\circ}$. Based on the choice of reference spectra, the quality of the estimates may also decrease for mixtures whose species' concentrations significantly differ from those selected as a reference in the CLS method.

The highest absolute error related to the prediction of the $\mathrm{NH}_{3}$ (aq) concentration can be justified by the low signal-tonoise ratio that characterizes the peak of this species (see Fig. 6) and that therefore renders its concentration estimates less accurate compared to that of the other components.

\subsection{Estimation of the ammonium bicarbonate concentration in aqueous ammonia solutions}

In aqueous ammonia solutions of ammonium bicarbonate (i.e. solutions whose representative point is on a isopleth line with $\zeta \geq 1$ in Fig. 1) the distribution of carbon species changes significantly according to the overall nitrogen to carbon ratio of the system. ${ }^{33}$ This phenomenon leads to spectral data that cannot be easily correlated to the overall $\mathrm{BC}$

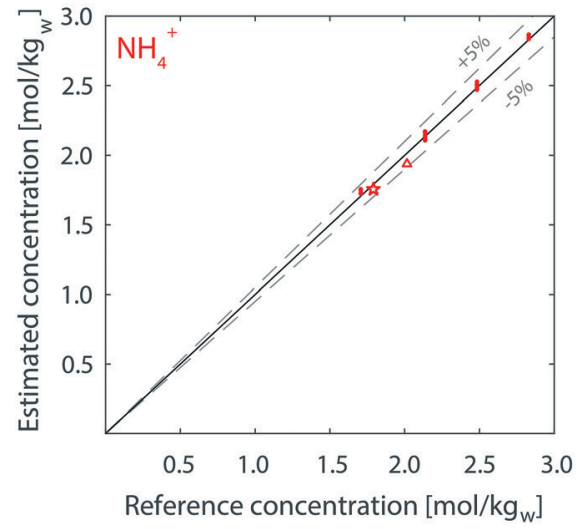

(a)

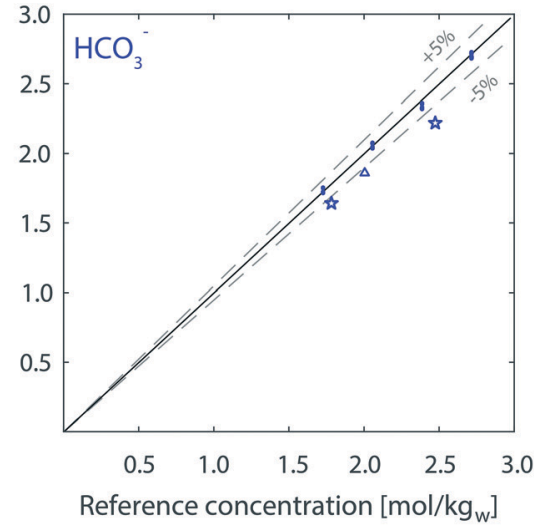

(b)

Fig. 8 Parity plots of the reference vs. estimated solute concentrations in the temperature range $6-23{ }^{\circ} \mathrm{C}$. (a) Concentration estimates of the $\mathrm{NH}_{4}{ }^{+}$ion, (b) concentration estimates of the $\mathrm{HCO}_{3}{ }^{-}$ion. Dots $(\bullet)$ refer to the in silico generated solutions, triangles $(\Delta)$ refer to the aqueous solution of $\mathrm{BC}\left(2 \mathrm{~mol} \mathrm{~kg}_{\mathrm{w}}{ }^{-1}\right)$, stars $(\star)$ refer to the real mixtures of binary salts, i.e. $\mathrm{NH}_{4} \mathrm{Cl}$ and $\mathrm{KHCO}_{3}$, at the concentrations of 1.75 mol $\mathrm{NH}_{4} \mathrm{Cl} \mathrm{kg}_{\mathrm{w}}{ }^{-1}$ and $1.75 \mathrm{~mol}_{\mathrm{KHCO}_{3}} \mathrm{~kg}_{\mathrm{w}}{ }^{-1}$, and of $1.75 \mathrm{~mol}_{\mathrm{NH}_{4} \mathrm{Cl}} \mathrm{kg}_{\mathrm{w}}{ }^{-1}$ and 2.50 mol $_{\mathrm{KHCO}_{3}} \mathrm{~kg}_{\mathrm{w}}{ }^{-1}$ respectively. 
concentration in the liquid phase, $m_{\mathrm{BC}}^{(1)}$, using a single PLS calibration model. Such challenge has therefore been overcome by building dedicated PLS calibrations for different nominal ammonia concentration $m_{\mathrm{NH}_{3}}^{\circ}$ in the solvent (i.e. different values of $\zeta$ ). These models implictly account for the liquid speciation and correlate the overall $\mathrm{BC}$ concentration to the baseline corrected $\mathrm{C}-\mathrm{OH}$ stretching band of the $\mathrm{HCO}_{3}{ }^{-}$ ion located at $1005 \mathrm{~cm}^{-1}$ in the infrared spectrum ${ }^{30}$ (Fig. 10a). In fact, this peak overlaps with the solvent band only, thus minimizing the interference with any other ionic species in solution. As shown in Fig. 10b, the ratio between the concentration of the $\mathrm{HCO}_{3}{ }^{-}$ion and of the total carbon species steadily decreases with increasing overall nitrogen content, thus reducing accordigly the intensity of the $\mathrm{HCO}_{3}{ }^{-}$ peak. Nevertheless, the method can potentially be used to estimate reliably the $\mathrm{BC}$ concentration in a wide range of nominal ammonia concentrations in the solvent. It must be acknowledged that the proposed calibration models are inherently dependent on the solvent composition, the information on the nominal ammonia concentration in the solvent must be known in order to properly exploit the model.

In this work, a total of three PLS regression models have been computed at values of nominal ammonia concentration in the solvent equal to 0,2 , and $3 \% \mathrm{wt}$, respectively. The training sets of the PLS calibrations are represented by the spectra of BC in aqueous ammonia solutions in a temperature range that covers both the undersaturated and the supersaturated conditions (see Tables 2 and 3). The models have been regressed including the information of the spectra of pure water, as well as the dependence of the IR spectra on temperature. During each experiment, a known amount of ammonium bicarbonate has been dissolved in the solution and spectral acquisition has been started shortly after reaching equilibrium. Then, a cooling rate of $10{ }^{\circ} \mathrm{C} \mathrm{h}^{-1}$ has been applied to the system, while measuring ATR-FTIR spectra every minute. The onset of primary nucleation has been monitored using FBRM measurements so that spectra measured after nucleation could be rejected from the training set of the PLSR models. For the sake of completeness the whole training data set is reported in the ESI. $\dagger$

The prediction capability of the ATR-FTIR calibration models has been assessed using independent BC solubility measurements. A first type of experiment consists in heating saturated aqueous ammonia solutions in presence of suspended $\mathrm{BC}$ at a rate of $2{ }^{\circ} \mathrm{C} \mathrm{h}^{-1}$ while collecting spectral data. A second type of experiment is based on the

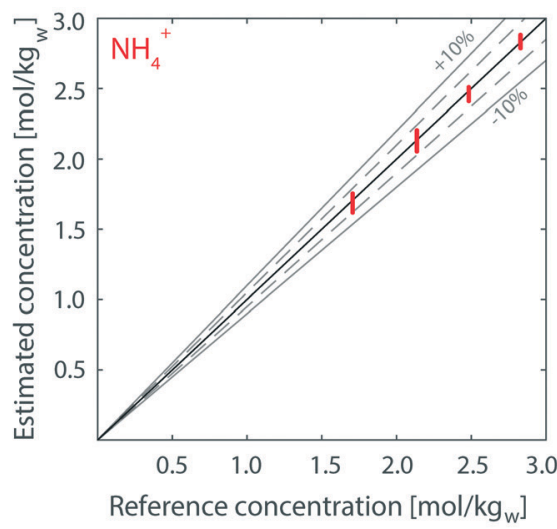

(a)

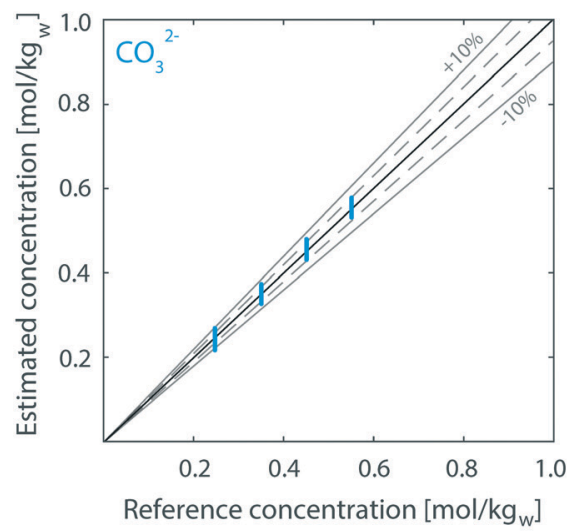

(c)

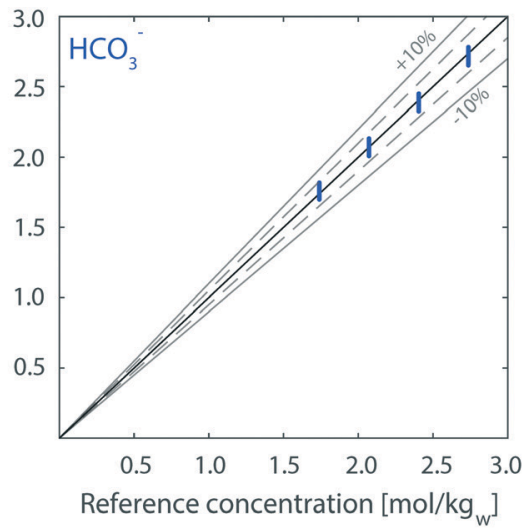

(b)

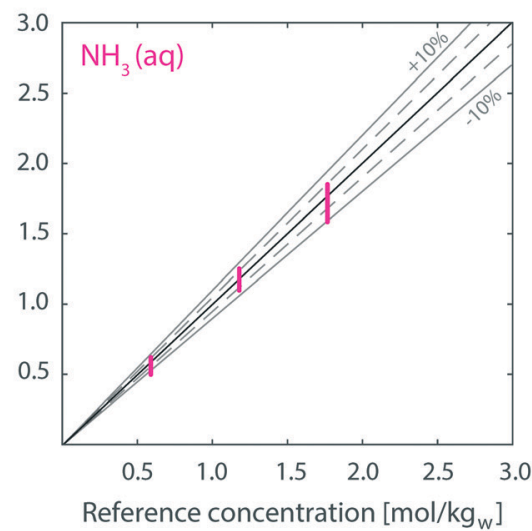

(d)

Fig. 9 Parity plots of the reference vs. estimated concentrations for multicomponent virtual mixtures: (a-d) concentration estimates of the $\mathrm{NH}_{4}{ }^{+}$, $\mathrm{HCO}_{3}{ }^{-}, \mathrm{CO}_{3}{ }^{2-}$ and $\mathrm{NH}_{3}(\mathrm{aq})$ species, respectively. 


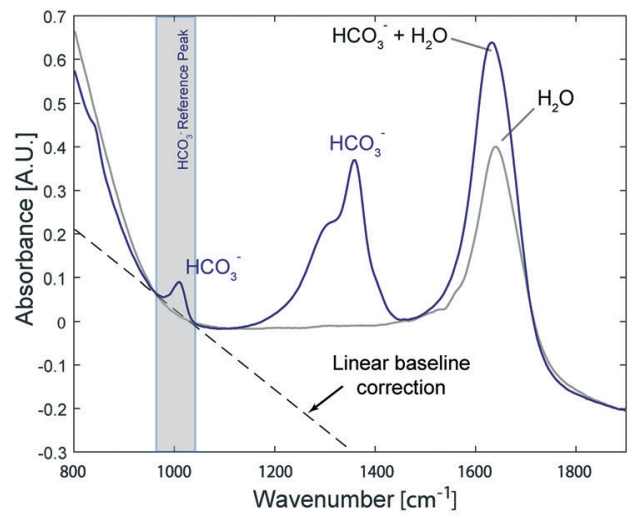

(a)

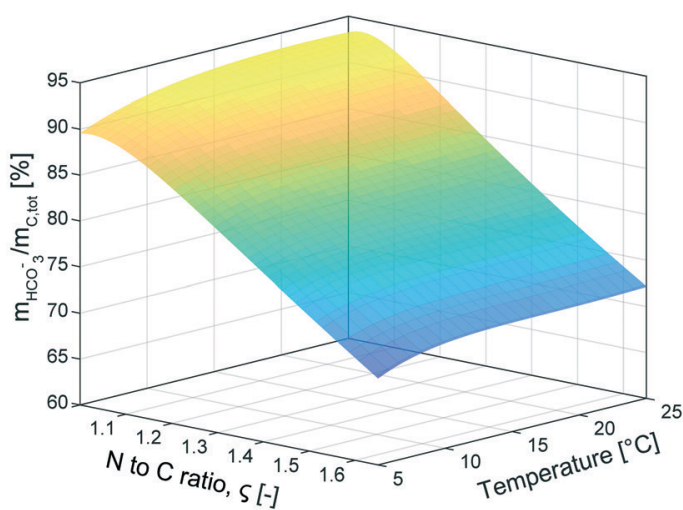

(b)

Fig. 10 (a) IR reference peak of the $\mathrm{HCO}_{3}{ }^{-}$ion (blue spectrum) used for the estimation of the overall ammonium bicarbonate concentration in aqueous ammonia solutions. The peak has good analytical potential for the estimation of the $\mathrm{HCO}_{3}{ }^{-}$ion concentration in solution. The spectrum of the solvent (gray spectrum) is reported for reference. (b) Percent distribution of the $\mathrm{HCO}_{3}{ }^{-}$species as a function of temperature and total nitrogen to carbon ratio $\zeta$ at a fixed total carbon concentration $\left(2 \mathrm{~mol} \mathrm{~kg}_{\mathrm{w}}{ }^{-1}\right)$ in solution. Calculations have been performed using the thermodynamic model proposed by Darde et al. ${ }^{6}$

measurement of the temperature at which the solid phase disappears. ${ }^{19}$ In this case, the FBRM signal has been used to detect complete dissolution of particles while slowly heating the suspension at a rate of $1^{\circ} \mathrm{C} \mathrm{h}^{-1}$.

Fig. 11a shows the ATR-FTIR-based solubility measurements (circles) carried out at a nominal ammonia content in the solvent equal to $0 \%, 2 \%$, and $3 \%$ wt (indicated with a colorcode), while the measurements based on the temperature at which the solid phase disappears are shown as filled dots. The effect of an ammonia enrichment of the solution results in a remarkable increase of the ammonium bicarbonate solubility.

The good agreement of the solubility measurements obtained with independent methods supports the applicability of the ATRFTIR calibration for the estimation of the overall $\mathrm{BC}$ concentration in solution. Fig. 11b provides a different representation of the $\mathrm{BC}$ solubility data in the $\mathrm{CO}_{2}-$ $\mathrm{NH}_{3}-\mathrm{H}_{2} \mathrm{O}$ ternary diagram as function of temperature and gives an indication of the operating region investigated experimentally.

\subsection{Speciation of ammonium bicarbonate in solution}

The speciation of saturated aqueous ammonia solutions of ammonium bicarbonate has been measured by applying the proposed CLS methodology for a nominal ammonia concentration in the solvent in the range $0-3 \%$ wt. For these mixtures the ratio between nitrogen to carbon species roughly spans values from 1 to 1.5 .

Systems in which the $\zeta$ ratio is less than unity (see Fig. 1) are characterized by a higher $\mathrm{CO}_{2}(\mathrm{aq})$ concentration in the liquid phase (compared to systems in which $\zeta$ is greater or equal to one) that leads to an increase of the value of $\mathrm{CO}_{2}$ partial pressure. The investigation of such systems, not addressed in this work, is therefore limited by the maximum pressure of the vessel.
5.6.1 Model implementation. Prior to the application of the CLS method to aqueous ammonia solutions of ammonium bicarbonate, the optimal set of adjustable parameters used to describe the IR bands of the carbamate ion (for which no prior knowledge is currently available from literature, see sec. 3.4) has been estimated by solving the following minimization problem:

$$
\underset{\sigma}{\operatorname{minimize}} \sum_{i}^{N_{\mathrm{s}}}\left\|\varepsilon_{i}\right\|_{2}
$$

where $\sigma$ is the vector of the broadnesses of the modeled carbamate bands, and $N_{\mathrm{s}}$ is the total number of measured spectra of the aqueous ammonia solutions of BC investigated. Then, the vector of optimal broadnesses $\hat{\sigma}$ has been integrated in the CLS model and used for the concentration estimates of the relevant species in solution.

In principle, the proposed CLS methodology can be applied to any aqueous solution containing unknown amounts of $\mathrm{CO}_{2}$ and $\mathrm{NH}_{3}$ as long as the validity of the Beer-Lambert law is preserved for each component's spectrum and the interactions among the individual spectra are negligible. In practice, the CLS approach is not applicable in a fully predictive mode since the overall nitrogen and carbon concentrations in solution are unknown.

In the specific case of aqueous ammonia solutions of ammonium bicarbonate the total carbon concentration, $m_{\mathrm{C},{ }_{\mathrm{OL}}}$ has been estimated from ATR-FTIR measurements exploiting the calibration method discussed in sec. 5.5, whereas the total nitrogen concentration $m_{\mathrm{N} \text {, }}$ has been computed using the information on the nominal ammonia concentration in the solvent, which is assumed to be known. Then, the overall carbon and nitrogen concentrations have been used together with the concentration estimates of the ammonium and bicarbonate ions, $\hat{c}_{\mathrm{NH}_{4}{ }^{+}}$and $\hat{c}_{\mathrm{HCO}_{3}}$, (retrieved by applying the 


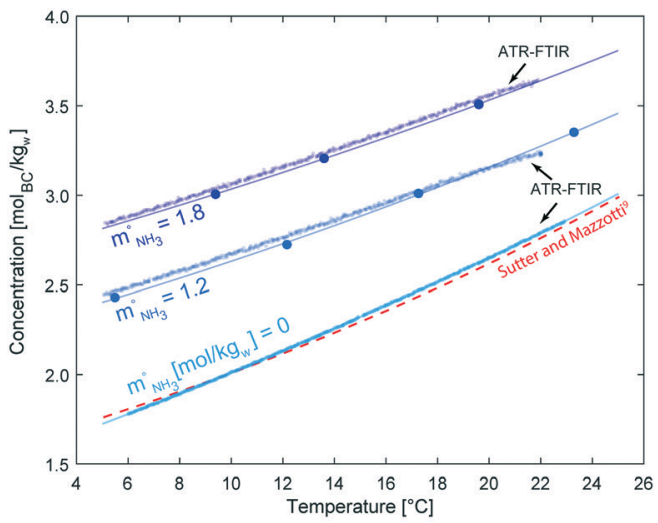

(a)

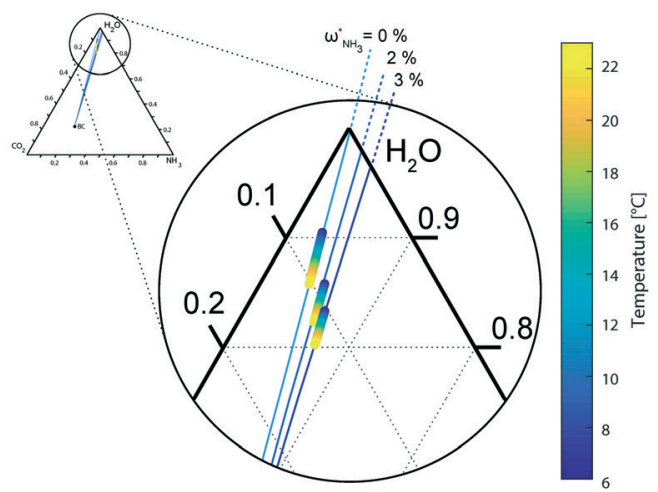

(b)

Fig. 11 Ammonium bicarbonate solubility in aqueous ammonia solutions as a function of temperature and nominal ammonia concentration in the solvent, $m_{\mathrm{NH}_{3}}^{\circ}$, (see blue colorcode). The solubility is based on a pure water mass basis. (a) ATR-FTIR-based solubility measurements (see arrows) and FBRM measurements of complete solid disappearance (filled dots). Solid curves are the interpolated solubility data, while the dotted red curve refers to the BC solubility in aqueous solution of Sutter and Mazzotti $^{9}$ (b) representation of the BC solubility data of Fig. $11 \mathrm{a}$ in the ternary diagram for the $\mathrm{CO}_{2}-\mathrm{NH}_{3}-\mathrm{H}_{2} \mathrm{O}$ system as a function of temperature. The blue lines are the operating lines that connect the composition of ammonium bicarbonate (BC) to aqueous ammonia solutions at different nominal ammonia concentration (see dashed lines).

CSL methodology proposed in sec. 4 to the spectrum of the unknown mixture) to solve the charge and mass balances in the liquid phase, eqn ((14)-(16), and eqn (17)), thus retrieving the concentration of the unknown species. Although the solution of the latter system of equations allows to obtain the complete speciation of the system, the values of the remaining degrees of freedom have been specified by introducing the following simplifications. For the case of aqueous solutions of $\mathrm{BC}$ the presence of $\mathrm{NH}_{3}(\mathrm{aq})$ has been neglected due to mild alkalinity of the system ${ }^{28,35}$ (see Fig. 1). Analogously, for the case of aqueous ammonia solutions of $\mathrm{BC}$ the contribution of the $\mathrm{CO}_{2}(\mathrm{aq})$ has been neglected in the material balance due to the basicity of these mixtures. Finally, the presence of $\mathrm{H}^{+}$and $\mathrm{OH}^{-}$ions has been omitted in the charge balance due to their low concentration in solution, typically in the order of $10^{-7} \mathrm{~mol} \mathrm{~kg}_{\mathrm{w}}{ }^{-1}$.
Note that the choice of using the ammonium and bicarbonate concentration estimates as an input for the material and charge balances stems from the fact that the CLS concentration estimates of these species are the most reliable ones due the spectroscopic properties of their characteristic IR peaks, i.e. the high absorptivity and the high signal-tonoise ratio in the region of wavenumbers of interest.

An alternative method to estimate the concentration of the bicarbonate ion relies on a PLS calibration based on the $\mathrm{HCO}_{3}{ }^{-}$peak located at $1005 \mathrm{~cm}^{-1}$ that, compared to the CLS methodology, does not require any intermediate modeling step of the spectrum of the mixture. Nevertheless, the estimation of the $\mathrm{NH}_{4}{ }^{+}$ion concentration, due to the high degree of overlap of the IR peak of this species with the spectra of the other solutes in solution, requires a modeling step of the spectrum of the unknown mixture.

5.6.2 Speciation in aqueous solutions of ammonium bicarbonate. As shown in Fig. 12, the spectral data of saturated aqueous ammonia solutions of BC (blue curves) is fitted consistently (red curves) in the entire range of operating conditions investigated. This is indicative of the absence of relevant interactions among the spectrum of the pure components and confirms the applicability of the proposed CLS method. The corresponding species concentrations have been estimated in the temperature range $6-23{ }^{\circ} \mathrm{C}$ and compared to the predictions of the thermodynamic models proposed by Thomsen and Rasmussen ${ }^{5}$ and Darde et al., ${ }^{6}$ respectively. Such mixtures have been obtained by slowly heating $\left(0.5{ }^{\circ} \mathrm{C} \mathrm{h}^{-1}\right)$ aqueous ammonia suspensions of BC in the temperature range investigated.

Aqueous solutions of $\mathrm{BC}$ are equimolar mixtures of $\mathrm{CO}_{2}$ and $\mathrm{NH}_{3}$ whose overall composition in the ternary diagram of Fig. 1 and 11b lies on the operating line that connects the composition of the BC salt to the vertex of pure water $(0 \% \mathrm{wt}$ ammonia in the solvent or $\zeta=1$ ). The measured speciation, indicated as dots in Fig. 13, reveals that the dominant species present in solution are the $\mathrm{NH}_{4}^{+}$and $\mathrm{HCO}_{3}{ }^{-}$ions, thus confirming the congruent solubility of ammonium bicarbonate in aqueous solution reported by Jänecke. ${ }^{1}$ The ratio $\hat{c}_{\mathrm{HCO}_{3}}{ }^{-} / \hat{c}_{\mathrm{NH}_{4}{ }^{+}}$is 0.95 at $6{ }^{\circ} \mathrm{C}$; it decreases for increasing values of temperature reaching a value of 0.92 at $23{ }^{\circ} \mathrm{C}$ due to the concomitant increment of the concentration of $\mathrm{CO}_{2}(\mathrm{aq})$ and $\mathrm{NH}_{2} \mathrm{COO}^{-}$whose presence slightly shifts the carbon and nitrogen distributions towards these species. Evidence of dissolved $\mathrm{CO}_{2}$ is confirmed by the presence of a marked antisymmetric stretching fundamental peak of $\mathrm{CO}_{2}(\mathrm{aq})$ located at $2343 \mathrm{~cm}^{-1}$ in the infrared spectrum (the interested reader is referred to the $\mathrm{ESI}_{\dagger} \dagger$ for further details). Finally, the trend followed by the estimated speciation is in agreement with the predictions of the thermodynamic models (indicated as dashed lines) in both qualitative and quantitative ways. Note that the concentrations of the $\mathrm{NH}_{3}(\mathrm{aq})$ and the $\mathrm{CO}_{3}{ }^{2-}$ ion have not been represented due to their negligible level in all these cases.

5.6.3 Speciation in aqueous ammonia solutions of ammonium bicarbonate. In aqueous ammonia solutions of $\mathrm{BC}$ the 


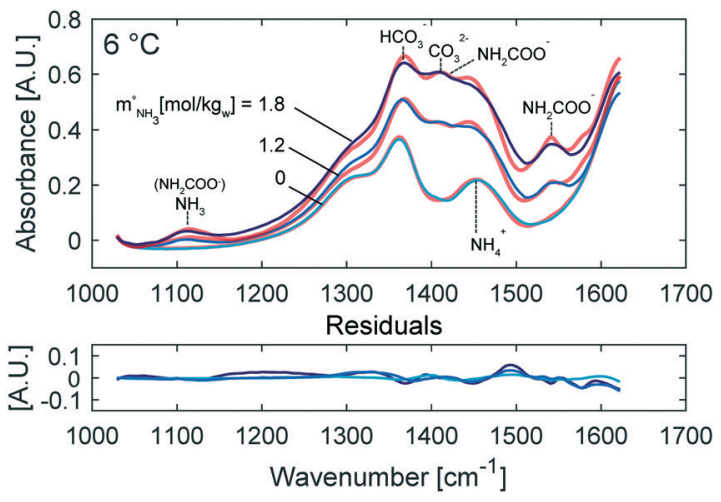

(a)
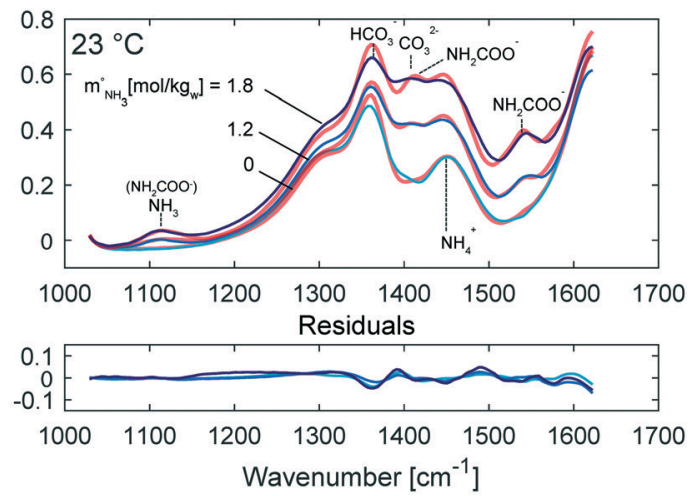

(b)

Fig. 12 Quality of fitting of the ATR-FTIR spectra of saturated aqueous ammonia solutions of BC at different temperatures. The range of ammonia concentration in the solvent varies between $0-1.8 \mathrm{~mol} \mathrm{~kg}_{\mathrm{w}}{ }^{-1}$. The red curves are the spectra resulting from the CLS fitting, while the blue curves are the experimental spectra of the mixtures (the colorcode refers to the nominal ammonia concentration of the solvent). (a) Fitting at $6{ }^{\circ} \mathrm{C}$, (b) fitting at $23{ }^{\circ} \mathrm{C}$. The plots underneath the fitted spectra show the residuals between the best fit and the experimental data.

shift of the carbon species distribution towards $\mathrm{CO}_{3}{ }^{2-}$ and $\mathrm{NH}_{2} \mathrm{COO}^{-}$is due to the presence of a stoichiometric excess of ammonia. Due to the kinetically controlled reaction of carbamate formation (eqn (8)), these mixtures require longer equilibration times when compared to equimolar aqueous solutions of $\mathrm{CO}_{2}$ and $\mathrm{NH}_{3}{ }^{33,36}$ this aspect must be taken into account while performing experiments not to underestimate the equilibrium carbamate concentration.

Fig. 13 shows (moving from left to right) how the carbon distribution in saturated aqueous ammonia solutions of BC changes from essentially bicarbonate only to an equilibrium mixture of bicarbonate, carbonate and carbamate ions ${ }^{10,11,33}$ as the concentration of non-stoichiometric ammonia increases. The concentration estimates of the different species (indicated as dots) are relative to a nominal ammonia concentration in the solvent of $1.2 \mathrm{~mol} \mathrm{~kg}_{\mathrm{w}}^{-1}$ and $1.8 \mathrm{~mol} \mathrm{~kg}_{\mathrm{w}}{ }^{-1}$ respectively, in the temperature range $6-23{ }^{\circ} \mathrm{C}$. Note that in these two cases, the experimental values of the $\mathrm{NH}_{4}{ }^{+}$concentration exceed slightly the range of concentrations used to build the model calibration for this species. However, literature data confirm the validity of the Beer-Lambert law for this species up to $5 \mathrm{~mol} \mathrm{~kg}_{\mathrm{w}}{ }^{-1}{ }^{10,11}$

Compared to the case of a pure aqueous solutions of $\mathrm{BC}$ $\left(m_{\mathrm{NH}_{3}}^{\circ}=0 \mathrm{~mol} \mathrm{~kg}_{\mathrm{w}}^{-1}\right)$, the presence of additional species such as $\mathrm{CO}_{3}{ }^{2-}, \mathrm{NH}_{2} \mathrm{COO}^{-}$, and $\mathrm{NH}_{3}$ (aq) can also be noticed by analyzing the IR spectra shown in Fig. 12. The carbonate ion peak appears as highly convoluted while the appearance of a visible carbamate peak (located at $1545 \mathrm{~cm}^{-1}$ ), which is pronounced even at low concentrations, indicates a high absorptivity of this band. ${ }^{11}$ Aqueous ammonia is present at a much lower concentration compared to its nominal value in the solvent, thus indicating that speciation into $\mathrm{NH}_{4}{ }^{+}$and $\mathrm{NH}_{2} \mathrm{COO}^{-}$occurred. Despite the low absorptivity of the aqueous ammonia band (see Fig. 5) and its overlap with one of the weakest $\mathrm{NH}_{2} \mathrm{COO}^{-}$peaks, the discrepancy between the reconciled concentration of aqueous ammonia and its CLS estimate has been found to be between $\pm 5 \%$. For the case of $\mathrm{CO}_{3}{ }^{2-}$ the difference lies between $15 \%$.
In general, both thermodynamic models from the literature describe the experimental trends quite well with the best quantitative agreement offered by the Thomsen model. Instead, Darde model slightly overestimates the carbamate concentration in the entire range of experimental conditions investigated, thus leading to a different distribution of the remaining nitrogen and carbon species in solution.

\subsection{Estimation of the Supersaturation of aqueous ammonia solutions of ammonium bicarbonate}

The speciation process occurring in the $\mathrm{CO}_{2}-\mathrm{NH}_{3}-\mathrm{H}_{2} \mathrm{O}$ system affects the several solid-liquid equilibria that can be established at the relevant conditions of temperature, pressure and composition of the system. In this study, the most stable solid that could form is ammonium bicarbonate ${ }^{1-3}$ and, as stated in sec. 2, the strong non-ideality of the liquid phase requires an activity-based approach for the description of all the phase equilibria. An important thermodynamic property involved in the description of the $\mathrm{BC}$ solid-liquid equilibrium, and of any solid-liquid equilibria in general, is the supersaturation $S$ defined as: $:^{37,38}$

$$
S=\frac{a_{\mathrm{NH}_{4}^{+}} a_{\mathrm{HCO}_{3}^{-}}}{a_{\mathrm{NH}_{4}^{+}}^{*} a_{\mathrm{HCO} O_{3}^{-}}^{*}}=\frac{K_{\mathrm{IP}}(\mathbf{c}, T)}{K_{\mathrm{SP}}(T)}
$$

where the superscript $*$ indicates quantities at solubility (solid-liquid phase equilibrium), $a_{i}$ is the activity of the $i$-th species, $K_{\mathrm{SP}}(T)$ is the thermodynamic solubility product of $\mathrm{BC}$ defined as:

$$
K_{\mathrm{SP}}(T)=\exp \left[-\frac{\Delta G_{\mathrm{BC}}(T)}{R T}\right]
$$

and $K_{\mathrm{IP}}$ is often referred to as the ionic product of ammonium bicarbonate in solution, function of the temperature and composition of the system. Its dependence on pressure 

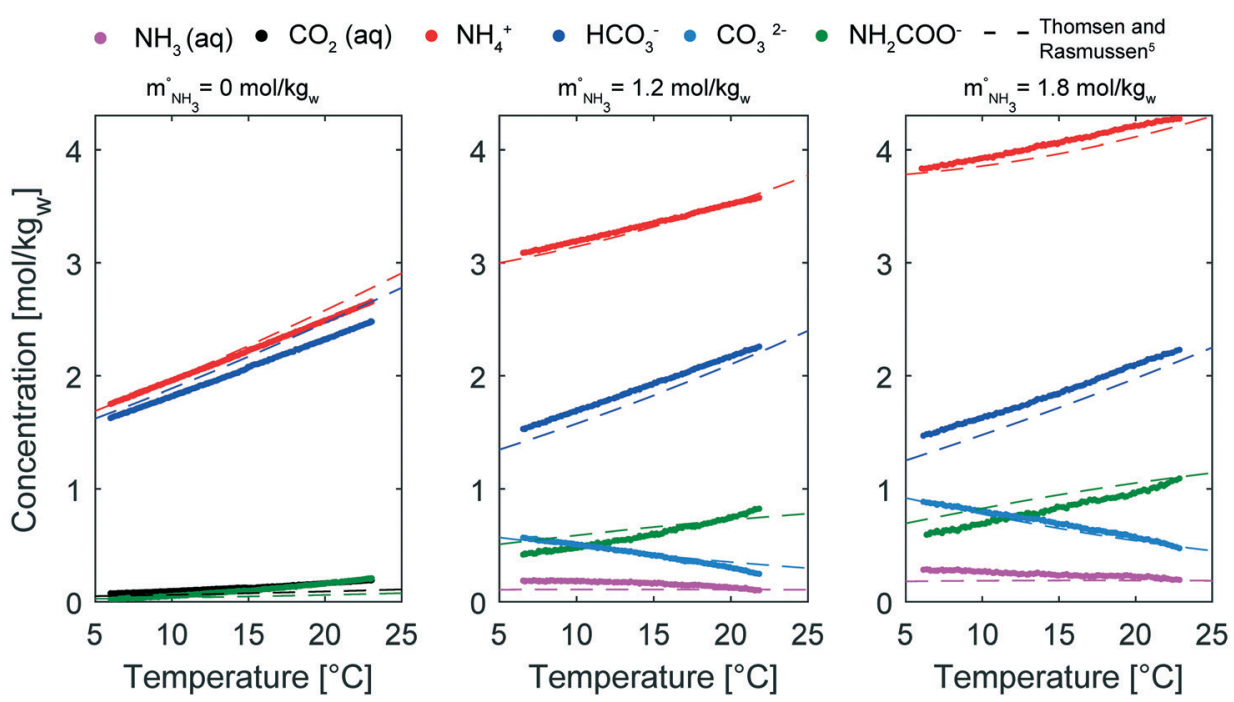

(a)
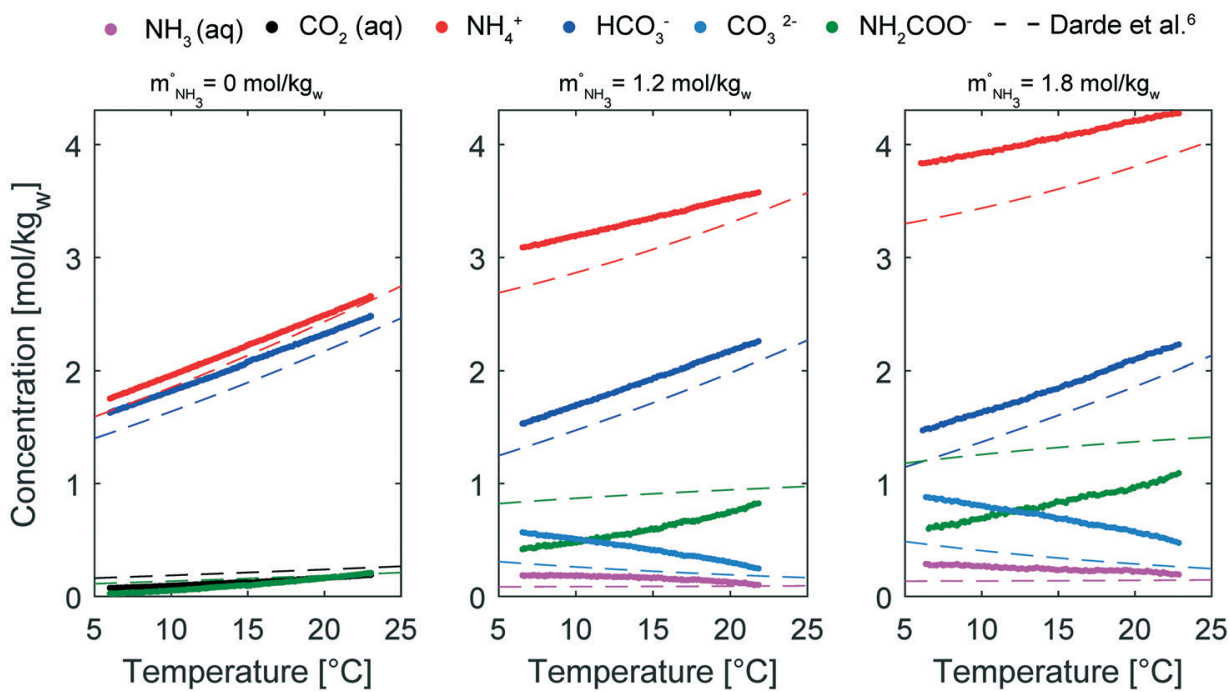

(b)

Fig. 13 Comparison of the ATR-FTIR speciation data (dots) of saturated aqueous ammonia solutions of ammonium bicarbonate and the predictions of thermodynamic models (dashed lines) in the temperature range $5-23^{\circ} \mathrm{C}$. (a) Comparison to the Thomsen model. ${ }^{5}$ (b) Comparison to the Darde model. ${ }^{6}$ The range of investigated ammonia concentration in the solvent varies between 0-1.8 mol kg ${ }^{-1}$.

is typically weak and for this reason neglected in this study. The term $\Delta G_{\mathrm{BC}}(T)$ in eqn (36) is the increment in standard state Gibbs free energy of formation of BC in aqueous solution, ${ }^{6}$ at temperature $T$ and $R$ is the ideal gas constant.

Fig. 14 shows a comparison between the experimental solubility of ammonium bicarbonate ${ }^{2}$ at $20^{\circ} \mathrm{C}$ (black boxes and circles) and those computed using the Thomsen model (green curve), the Darde model (blue curve), and a refitted version of the Thomsen model (red curve) built in this work and discussed in the following. The solid-liquid envelopes of the $\mathrm{CO}_{2}-\mathrm{NH}_{3}-\mathrm{H}_{2} \mathrm{O}$ system have been obtained by performing solid-liquid flash calculations using the abovementioned models (see $\mathrm{ESI} \dagger$ for further details).

As it can be noted in Fig. 14, both Thomsen and Darde models slightly underpredict the measured ammonium bicar- bonate solubility (see magnification of the ternary diagram region). Such local inaccuracies, although negligible in the context of overall process simulations, ${ }^{7,39}$ must be minimized for the monitoring and the kinetic investigation of BC crystallization processes for which an accurate computation of the supersaturation is required. To achieve this, we performed a re-estimation of the parameters of the Thomsen model (that provides the best representation of the speciation data measured in this work) with the aim of increasing the accuracy of the description of the solid-liquid equilibrium of $\mathrm{BC}$ in aqueous ammonia solutions. In detail, a subset of extendedUNIQUAC interaction parameters, represented by the matrices $\mathbf{u}^{0}$ and $\mathbf{u}^{T}$ of the Thomsen model reported in Tables 4 and 5 , has been optimized while keeping unaltered the remaining parameters and thermodynamic properties of the model. 
Experimental data of aqueous ammonia solutions of BC at saturated conditions have been used in the following optimization problem: performed using the optimizer fmincon in the Matlab Optimization Toolbox ${ }^{40}$ with an initial guess provided by the extended-UNIQUAC parameter set of the Thomsen model.

$$
\underset{\mathbf{u}^{0}, \mathbf{u}^{T}}{\operatorname{minimize}} \sum_{j=1}^{N_{\mathrm{e}}} \sum_{i=2}^{n-1} \sum_{k=1}^{N_{\mathrm{obv}}}\left(\frac{c_{j, i, k}^{\text {calc }}-c_{j, i, k}^{\text {exp } *}}{c_{j, i, k}^{\exp , *}}\right)^{2}+\sum_{j=1}^{N_{\mathrm{e}}} \sum_{k=1}^{N_{\mathrm{obv}}}\left[\frac{\Delta G_{\mathrm{BC}}\left(T_{j, k}\right)+R T_{j, k} \ln \left(K_{\mathrm{IP}, j, k}\right)}{R T_{j, k}}\right]^{2}
$$

where $c_{i}^{\text {calc }}, c_{i}^{\exp }$, and $K_{\mathrm{IP}}$ are the model predictions of the concentration of the $i$-th species, the one measured, and the ionic product of ammonium bicarbonate. The variables $n, N_{\mathrm{e}}$ and $N_{\text {obv }}$ are the number of species, the number of experimental conditions investigated (i.e. different nominal concentrations of ammonia in the solvent), and the number of observations of each species at the relevant experimental conditions, respectively. The data set to be fitted consisted of 13 concentration data points $\left(N_{\text {obv }}\right)$ for each species collected in the temperature range $6-20{ }^{\circ} \mathrm{C}$ at three different nominal ammonia concentration in the solvent, i.e. 0,2 , and $3 \% \mathrm{wt}$.

The first term of the objective function in eqn (37) accounts for the speciation data to be regressed, while the second term is used to impose the values of the BC solubility product to be fitted during the optimization. The speciation has been computed by solving the liquid speciation equilibria (eqn (4)-(8)) while neglecting all the solid-liquid equilibria (eqn (9)-(12)). The unconstrained optimization has been
As shown in Fig. 15, the optimal set of regressed parameters allowed for a good fitting of the experimental speciation data as well as of the solubility product of $\mathrm{BC}$ in the entire range of operating conditions investigated.

It is worth noting that since the optimization procedure does not include any solubility data of the additional solids that might form, the refitted Thomsen model proposed in this work is unable to describe accurately the solubilities of the different salts outside the ammonium bicarbonate region. Although being able to capture the experimental BC solubility ${ }^{2}$ (black boxes and circles) significantly well (see Fig. 14), it progressively underestimates the salts' solubilities as the equivalent ammonia content in the system increases. Not surprisingly, Darde model, by being fitted on a much larger set of experimental data, ${ }^{6}$ is capable of describing effectively the entire set of solidliquid equilibria.

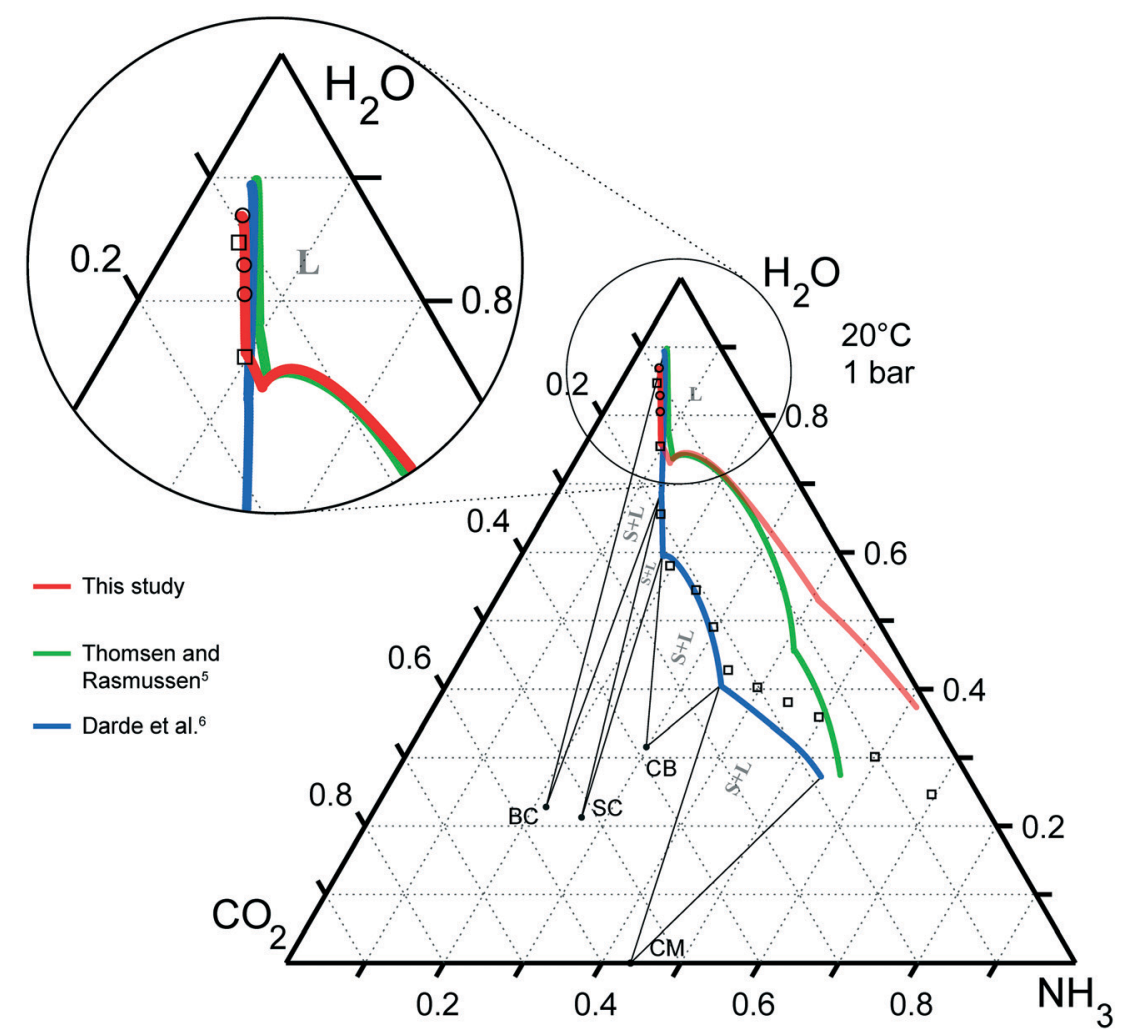

Fig. 14 Solubility curves of the different salts in the $\mathrm{CO}_{2}-\mathrm{NH}_{3}-\mathrm{H}_{2} \mathrm{O}$ system at $20^{\circ} \mathrm{C}$ and 1 bar computed with the Darde model ${ }^{6}$ (blue curve), the Thomsen model ${ }^{5}$ (green curve), and the refitted Thomsen model (red curve) respectively. Black boxes ( $\square$ ) indicate the solid-liquid equilibrium data by Jänecke, ${ }^{2}$ while black circles $(O)$ indicate the ammonium bicarbonate solubility measured in this work. 
Table 4 Extended-UNIQUAC interaction energy parameters $\mathbf{u}_{i j}^{0}\left(\mathbf{u}_{i j}=\mathbf{u}_{i j}^{0}+\mathbf{u}_{i j}^{T}(T-298.15)\right.$ and $\left.\mathbf{u}_{i j}^{0}=\mathbf{u}_{j i}^{0}\right)$. The values of parameters in bold-italics have been changed from the original version on the model ${ }^{5}$

\begin{tabular}{|c|c|c|c|c|c|c|c|c|c|}
\hline$u_{i j}^{0}$ & $\mathrm{H}_{2} \mathrm{O}$ & $\mathrm{NH}_{3}(\mathrm{aq})$ & $\mathrm{CO}_{2}(\mathrm{aq})$ & $\mathrm{NH}_{4}^{+}$ & $\mathrm{H}^{+}$ & $\mathrm{OH}^{-}$ & $\mathrm{CO}_{3}{ }^{2-}$ & $\mathrm{HCO}_{3}^{-}$ & $\mathrm{NH}_{2} \mathrm{COO}^{-}$ \\
\hline $\mathrm{H}_{2} \mathrm{O}$ & 0 & & & & & & & & \\
\hline $\mathrm{NH}_{3}(\mathrm{aq})$ & 774.41 & 1140.20 & & & & & & & \\
\hline $\mathrm{CO}_{2}(\mathrm{aq})$ & 205.32 & 2500.00 & 40.52 & & & & & & \\
\hline $\mathrm{NH}_{4}{ }^{+}$ & 142.58 & 1010.60 & -5.05 & 0 & & & & & \\
\hline $\mathrm{H}^{+}$ & $10^{5}$ & $10^{10}$ & $10^{10}$ & $10^{10}$ & 0 & & & & \\
\hline $\mathrm{OH}^{-}$ & 600.50 & 2046.80 & 2500.00 & 1877.90 & $10^{10}$ & 1562.90 & & & \\
\hline $\mathrm{CO}_{3}^{2-}$ & 232.71 & 1662.40 & 2500.00 & 226.60 & $10^{10}$ & 1588.00 & 1458.30 & & \\
\hline $\mathrm{HCO}^{3-}$ & 625.93 & 3641.90 & 767.81 & 643.24 & $10^{10}$ & 2500.00 & 800.01 & 771.04 & \\
\hline $\mathrm{NH}_{2} \mathrm{COO}^{-}$ & 1.27 & 1006.40 & 2500.00 & 85.21 & $10^{10}$ & 2500.00 & 2500.00 & 612.95 & 1405.20 \\
\hline
\end{tabular}

Table 5 Extended-UNIQUAC interaction energy parameters $\mathbf{u}_{i j}^{T}\left(\mathbf{u}_{i j}=\mathbf{u}_{i j}^{0}+\mathbf{u}_{i j}^{T}(T-298.15)\right.$ and $\left.\mathbf{u}_{i j}^{T}=\mathbf{u}_{j i}^{T}\right)$. The values of parameters in bold-italics have been changed from the original version on the model $^{5}$

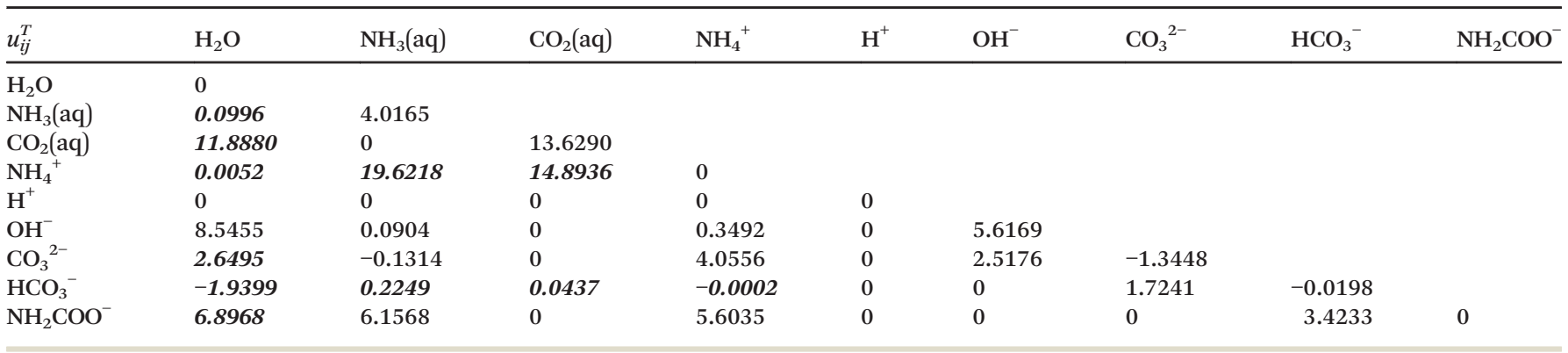

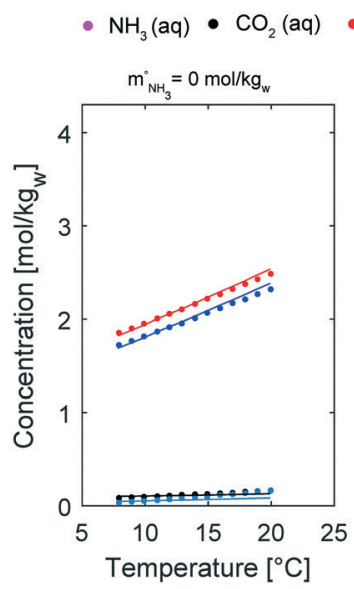

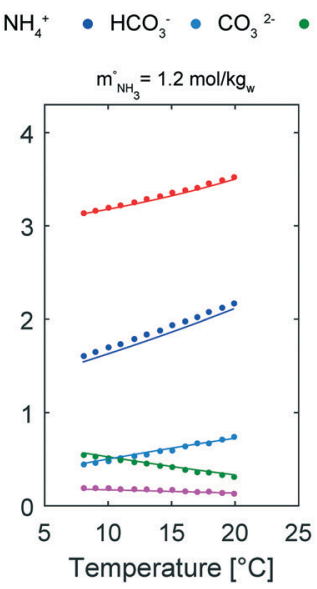

(a)

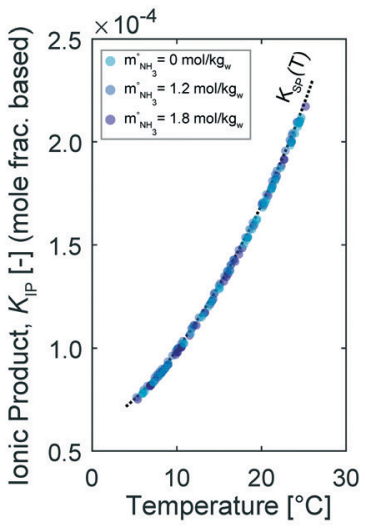

(b)

Fig. 15 Performance of the refitted speciation model (see sec. 5.7) over the temperature range $6-20^{\circ} \mathrm{C}$. (a) ATR-FTIR speciation data (dots) and model predictions (lines) of the species' concentration in saturated aqueous ammonia solutions of ammonium bicarbonate. The ammonia concentration in the solvent varies from 0 to $1.8 \mathrm{~mol} \mathrm{~kg}_{\mathrm{w}}{ }^{-1}$ moving from left to right. (b) lonic product of BC (dots) computed along the solubility curves of BC in Fig. 11a using the refitted Thomsen model presented in this work. The colorcode indicates the value of the nominal ammonia concentration in the solvent. The good overlap with the thermodynamic solubility product (dashed black line), $K_{\mathrm{SP}}$, indicates that the capacity of the model of describing accurately the solid-liquid equilibrium of ammonium bicarbonate in aqueous ammonia solutions.

\section{Conclusions}

In this article, a methodology that allows to determine the speciation of aqueous ammonia solutions of ammonium bicarbonate using in situ ATR-FTIR spectroscopy measurements has been presented. The determination of the liquid composition of such systems, regardless of the type of analytical technique exploited to measure it, poses several challenges.
Among them, the high volatility of the solutes, i.e. $\mathrm{CO}_{2}$ and $\mathrm{NH}_{3}$, requires to operate in a sealed reactor to minimize the material loss to the vapor phase, and the extent of the speciation in the liquid phase results, in general, in a complex overlap of the IR bands of the solutes in the infrared spectrum. A CLS methodology has therefore been used to segregate the contribution of each species to the IR signal of the mixture, and to estimate the concentration of the individual 
components in solution. This modeling approach, although simplified, is grounded on a physical description of the system and requires the estimation of fewer model parameters when compared to more complex modeling techniques such as the ones proposed by Lichtfers and Rumpf ${ }^{10,11}$ and Kriesten et al. ${ }^{41,42}$ As a matter of fact, the model's accuracy is expected to decrease as the absorbance of the individual species deviates from the values used as an internal reference of the CLS model (see eqn (20)), thus making it difficult to extend the use of the proposed methodology to a wide range of compositions in the $\mathrm{CO}_{2}-\mathrm{NH}_{3}-\mathrm{H}_{2} \mathrm{O}$ system.

For the purposes of our experimental investigation, the quality of the CLS fitting of the spectra has been used as the main criterion to assess the reliability of the concentration estimates, and the agreement between the ATR-FTIR measurements and the results of the speciation models available in the literature ${ }^{5,6}$ confirms the validity of the proposed methodology that could be applied for reaction kinetics monitoring purposes, for instance.

The solubility and speciation data measured for saturated aqueous ammonia solutions of $\mathrm{BC}$ have been used to improve the accuracy of the available thermodynamic models in the description of the $\mathrm{BC}$ solid-liquid equilibrium in aqueous ammonia solutions, thus allowing for a precise estimation of the $\mathrm{BC}$ supersaturation during crystallization processes.

Ultimately, this work paves the way for the estimation of the crystallization kinetics of ammonium bicarbonate in aqueous ammonia solutions essential for the design and control of solid formation in ammonia-based $\mathrm{CO}_{2}$ capture processes. ${ }^{7,8}$

\section{Conflicts of interest}

There are no conflicts to declare.

\section{Acknowledgements}

Support from the Swiss Commission for Technology and Innovation (KTI. 1155000150) within the SCCER-EIP (Swiss Competence Center for Energy Research - Efficiency of Industrial Processes) is gratefully acknowledged. Additionally, the authors thank Prof. Kaj Thomsen (Department of Chemical and Biochemical Engineering, Technical University of Denmark) for making the thermodynamic model available, Daniel Sutter, José Francisco Peréz Calvo and Ashwin Kumar Rajagopalan for the many fruitful discussions, Daniel Sutter again for a careful reading of the manuscript, and Daniel Trottmann, Markus Huber and the ETH NMR Service for the technical support.

\section{References}

1 E. Jänecke, Z. Elektrochem. Angew. Phys. Chem., 1929, 35, 716-728.

2 E. Jänecke, Z. Elektrochem. Angew. Phys. Chem., 1929, 35, 332-334.

3 E. Jänecke and E. Rahlfs, Z. Elektrochem. Angew. Phys. Chem., 1930, 36, 645-654.
4 E. Jänecke and E. Rahlfs, Z. Elektrochem. Angew. Phys. Chem., 1932, 38, 9-12.

5 K. Thomsen and P. Rasmussen, Chem. Eng. Sci., 1999, 54, 1787-1802.

6 V. Darde, W. J. M. van Well, E. H. Stenby and K. Thomsen, Ind. Eng. Chem. Res., 2010, 49, 12663-12674.

7 D. Sutter, M. Gazzani and M. Mazzotti, Faraday Discuss, 2016, 192, 59-83.

8 F. Milella, M. Gazzani, D. Sutter and M. Mazzotti, Ind. Eng. Chem. Res., 2018, 57, 11712-11727.

9 D. Sutter and M. Mazzotti, Cryst. Growth Des., 2017, 17, 3048-3054.

10 U. Lichtfers and B. Rumpf, Chem. Ing. Tech., 2000, 72, 1526-1530.

11 U. Lichtfers, PhD thesis, Universität Kaiserslautern, 2000.

12 J. Cornel, C. Lindenberg and M. Mazzotti, Ind. Eng. Chem. Res., 2008, 47, 4870-4882.

13 Z. K. Nagy and R. D. Braatz, Annu. Rev. Chem. Biomol. Eng., 2012, 3, 55-75.

14 N. Wen and M. H. Brooker, J. Phys. Chem., 1995, 99, 359-368.

15 M. Halstensen, H. Jilvero, W. N. Jinadasa and K.-J. Jens, J. Chem., 2017, 2017, 1-13.

16 W. W. Rudolph, G. Irmer and E. Königsberger, Dalton Trans., 2008, 900-908.

17 Q. Zhao, S. Wang, F. Qin and C. Chen, Ind. Eng. Chem. Res., 2011, 50, 5316-5325.

18 D. Sutter, M. Gazzani and M. Mazzotti, Chem. Eng. Sci., 2015, 133, 170-180.

19 P. Barrett and B. Glennon, Chem. Eng. Res. Des., 2002, 80, 799-805.

20 K. Nakamoto, Handb. Vib. Spectrosc., 2006, 1872-1892.

21 A. R. Davis and B. G. Oliver, J. Solution Chem., 1972, 1, 329-339.

22 E. Pretsch, P. Bühlmann and M. Badertscher, Structure Determination of Organic Compounds Tables of Spectral Data, Springer, Berlin, Heidelberg, 2009.

23 C. Hisatsune, Can. J. Chem., 1984, 62, 945-948.

24 D. L. Frasco, J. Chem. Phys., 1964, 41, 2134-2140.

25 M. Ekimova, W. Quevedo, Ł. Szyc, M. Iannuzzi, P. Wernet, M. Odelius and E. T. J. Nibbering, J. Am. Chem. Soc., 2017, 139, 12773-12783.

26 B. Schrader, Vib. Spectrosc., 1996, 11, 163.

27 F. O. Libnau, O. M. Kvalheim, A. A. Christy and J. Toft, Vib. Spectrosc., 1994, 7, 243-254.

28 D. A. Skoog, F. J. Holler and S. R. Crouch, Fundamentals of analytical chemistry, Thomson-Brooks/Cole, 2004, pp. 251263.

29 T. J. Wolery, EQ3/6 A Software Package for Geochemical Modeling, Lawrence Livermore National Lab., Livermore, CA, 2010.

30 M. Falk and A. G. Miller, Vib. Spectrosc., 1992, 4, 105-108.

31 D. M. Haaland and E. V. Thomas, Anal. Chem., 1988, 60, 1193-1202.

32 Y. Bard, Nonlinear Parameter Estimation, 1974, pp. 63-70.

33 P. E. Holmes, M. Naaz and B. E. Poling, Ind. Eng. Chem. Res., 1998, 37, 3281-3287. 
34 F. Mani, M. Peruzzini and P. Stoppioni, Green Chem., 2006, 8, 995.

35 D. D. Perrin, Pure Appl. Chem., 1969, 20, 1-2.

36 N. McCann, D. Phan, X. Wang, W. Conway, R. Burns, M. Attalla, G. Puxty and M. Maeder, J. Phys. Chem. A, 2009, 113, 5022-5029.

37 D. Kashchiev, Nucleation - basic theory with applications, Butterworth Heinemann, 2000.

38 A. S. Myerson, Handbook of Industrial Crystallization, Butterworth-Heinemann, 2002.
39 V. Darde, B. Maribo-Mogensen, W. J. van Well, E. H. Stenby and K. Thomsen, Int. J. Greenhouse Gas Control, 2012, 10, 74-87.

40 MATLAB 9.2 and Optimization Toolbox 7.6, The MathWorks, Inc., Natick, MA, 2017.

41 E. Kriesten, D. Mayer, F. Alsmeyer, C. Minnich, L. Greiner and W. Marquardt, Chemom. Intell. Lab. Syst., 2008, 93, 108-119.

42 E. Kriesten, F. Alsmeyer, A. Bardow and W. Marquardt, Chemom. Intell. Lab. Syst., 2008, 91, 181-193. 